\title{
Article \\ Effects of Strontium Content on the Microstructure and Ionic Conductivity of Samarium-Doped Ceria
}

\author{
Toby Sherwood and Richard T. Baker* \\ School of Chemistry, University of St Andrews, North Haugh St Andrews, Fife, Scotland KY16 9ST, UK; \\ tobysherwood@outlook.com \\ * Correspondence: rtb5@St-andrews.ac.uk; Tel.: +44-1334-463899; Fax: +44-1334-463808
}

\begin{abstract}
Due to its high oxygen ion conductivity at elevated temperatures, samarium-doped ceria (SDC) is a very promising material for application in solid state electrochemical devices and especially in the electrolytes of solid oxide fuel cells. Several prior studies have reported a further improvement in the ionic conductivity of SDC on doping with small amounts of strontium. It is suggested that strontium acts as a sintering aid-improving the microstructure of SDC-and as a scavenger of silicon impurities, decreasing its tendency to form resistive phases at grain boundaries. However, because of the range of preparation methods and the resulting differences in microstructure and silicon levels, some inconsistencies exist in the literature. Furthermore, the effect of strontium on the intrinsic (bulk) conductivity of SDC is not often discussed. To address these issues, a systematic, combined microstructural and conductivity study has been performed on a compositional series with a range of strontium contents, $\mathrm{Ce}_{0.8-\mathrm{x}} \mathrm{Sm}_{0.2} \mathrm{Sr}_{\mathrm{x}} \mathrm{O}_{2-\delta}(\mathrm{x}=0,0.002,0.005,0.01,0.02,0.03,0.04)$. A low temperature synthesis affording products with low silicon was employed. Total bulk and grain boundary conductivity data were obtained over a wide temperature range. Increasing strontium content caused a general decrease in total and intrinsic conductivity, but there was an improvement in grain boundary conductivity at the lowest strontium levels. These results were interpreted by reference to the microstructures using, among other parameters, the blocking, and normalised blocking, factors.
\end{abstract}

Keywords: solid oxide fuel cell; oxygen ion conductor; electrolyte; impedance spectroscopy; ceria; strontium

Academic Editor: Aleksey

Yaremchenko

Received: 4 June 2021

Accepted: 5 August 2021

Published: 10 August 2021

Publisher's Note: MDPI stays neutral with regard to jurisdictional claims in published maps and institutional affiliations.

Copyright: (C) 2021 by the authors Licensee MDPI, Basel, Switzerland. This article is an open access article distributed under the terms and conditions of the Creative Commons Attribution (CC BY) license (https:// creativecommons.org/licenses/by/ $4.0 /)$.

\section{Introduction}

Solid oxide fuel cells (SOFC) are of great interest because of their ability to efficiently and cleanly convert the chemical potential energy of a fuel and oxidant directly into electrical energy and useful heat [1-4]. There is interest in reducing the operating temperature of SOFCs [5]. At lower temperatures, cheaper metallic interconnects and supports can be used and the rates of undesirable solid state reactions, which degrade performance, are decreased. The electrolyte, which is usually an oxygen ion conductor, is an important component of the SOFC and largely determines the operating characteristics of the fuel cell. Early SOFC were mostly based on yttria-stabilised zirconia (YSZ) electrolytes and operate at $800-1000{ }^{\circ} \mathrm{C}$ [6]. A reduction in operating temperature to below $600{ }^{\circ} \mathrm{C}$ is desirable in order to realise the benefits outlined above. Lanthanide-doped ceria-based electrolytes display high ionic conductivities at these temperatures and have been used successfully in the manufacture of SOFCS [7,8]. Gadolinium and samarium are the most common dopants used in ceria electrolytes, as they give rise to some of the highest conductivities, an order of magnitude higher than for YSZ at $600{ }^{\circ} \mathrm{C}[6,9]$. Despite the success of these materials, clearly there is still an advantage in developing materials with even higher conductivity to either reduce operating temperatures or increase power output. As the limits of conductivity in ceria doped with a single species are approached, there is interest in whether doping with multiple species can result in higher conductivities. 
A number of papers have been published since 2007 looking at the effects of co-doping with strontium in lanthanide-doped ceria [10-23]. Doping strategies include substituting strontium for the co-dopant only, substituting strontium for cerium only, substituting strontium for equal molar fractions of the co-dopant and cerium and substituting half as much strontium as the mole fraction of cation removed. The choice of strategy affects the variation in oxygen vacancy concentration, $\left[\mathrm{V}_{\mathrm{O}}\right]$, and average cation radius.

Initial studies by Lane et al. [10] and Kim et al. [12] considered strontium co-doping as a method to reduce the deleterious effects of silicon impurities on the conductivity of gadolinium doped ceria [10,12]. Silicon is a common and ubiquitous element and often occurs as an impurity in many of the simple oxides and nitrates—of mineral origin —employed as starting materials for the preparation of SOFC electrolyte materials. In addition to this, silicon can be incorporated during milling and grinding of precursor solids with Si-containing media, and from treatments, especially at high temperature, in glass and ceramic containers. Co-doping with just a few cation percent of strontium was shown to be extremely effective, nearly eliminating the effects of silicon impurities. This effect was said by Lane et al. to be caused by the incorporation of silicon into a second phase, which was suggested to form at grain boundary triple points, leaving most of the boundary silicon-free, and therefore able to conduct freely [10]. However, Kim et al. suggested that it was unclear if this was definitely the mechanism [12]. These authors also noted an improvement in sinterability when strontium was added, and this has since been confirmed by almost all sintering studies on strontium co-doping. Subsequently, a number of studies have looked more specifically at the effects of strontium co-doping on conductivity. All studies showed an increase in total conductivity for at least one sample with strontium co-doping compared to a singly doped sample $[10-17,19,20,22]$. More generally, however, if co-doping is to be shown to be beneficial to conductivity, then it needs to result in materials with conductivities higher than those of the best singly doped materials. Only one of the strontium co-doped materials in the literature shows total conductivity comparable with the best singly doped materials [22]. Comparing the most conductive strontium co-doped sample to the singly doped sample in each study shows that in most cases, the increase in total conductivity was as a result of an increase in the grain boundary conductivity only. Only one study showed a significant increase in the intrinsic, bulk conductivity of the most conductive sample [22], whilst two showed slight increases [17,20], and the remainder either showed it to be unchanged or decreased $[10,12,13,16,20]$, or did not report bulk conductivities [11,14]. It is generally agreed that the improved grain boundary conductivity observed in all the studies can be explained by the role of strontium as a silicon scavenger and sintering aid. Additional explanations for increased conductivity are however suggested by some studies. Yeh et al. state that doping increases the radius of oxygen vacancies and so widens the oxygen-conducting channels [11], whilst Gao et al. [19] attribute increased conductivity to a combination of increased oxygen vacancy concentration and a suppression of ordering of vacancies due to changes in the configurational entropy reported by Yamamura et al. [24]. Jaiswal et al. [22] also cite the ordering effect.

The current study is designed to address the inconsistencies in the published conductivity values for $\mathrm{Sr}$ co-doped materials. The differences in conductivity are thought to be due to variation in preparation methods causing differences in the microstructure and impurity levels - especially between studies—which makes it difficult to determine which parameters control ionic conductivity. Therefore, a combined microstructural and conductivity study has been carried out, in order to clarify the relationships between chemical composition, microstructure and ionic conductivity. To reduce the potential influence of impurities and of variations in starting powder microstructure on the conductivity results, the ceramic precursor powders were synthesised by the citrate-nitrate method described by Kosinski and Baker [25]. This method yields very pure powders with fine and reproducible microstructure. In order to make a good comparison with existing studies the most commonly used doping strategy of replacing $\mathrm{Ce}$ for $\mathrm{Sr}$ was used giving the compositional series $\mathrm{Ce}_{0.8-} \mathrm{Sm}_{0.2} \mathrm{Sr}_{x} \mathrm{O}_{2-\delta}$. The range of $\mathrm{Sr}$ concentrations was chosen to 
include particularly low concentrations of $\mathrm{Sr}, \mathrm{x}=0.002$ and $\mathrm{x}=0.005$ as most previous studies which looked at co-doping with a range of strontium concentrations showed the largest increase in total conductivity for the sample doped with the lowest fraction of strontium $[11,13,14,17,19,20,22]$. The lowest dopant concentrations studied previously were 1 cation $\%[10,13,16,20]$. It was decided to investigate strontium doping levels below this value in order to see whether there was an advantage to doping in this range.

\section{Experimental}

Mixed oxide powders of $\mathrm{Ce}_{0.8-\mathrm{x}} \mathrm{Sm}_{0.2} \mathrm{Sr}_{\mathrm{x}} \mathrm{O}_{2-\delta}$ with $\mathrm{x}=0$ (Sr00), 0.002 (Sr02), 0.005 (Sr05), 0.01 (Sr10), 0.02 (Sr20), 0.03 (Sr30) and 0.04 (Sr40) were synthesised by a citrate-nitrate complexation method. $\mathrm{Sm}\left(\mathrm{NO}_{3}\right)_{3} \bullet 6 \mathrm{H}_{2} \mathrm{O}$ (Alfa Aesar, Haverhill, MA, USA, 99.9\%), $\mathrm{Ce}\left(\mathrm{NO}_{3}\right)_{3} \bullet 6 \mathrm{H}_{2} \mathrm{O}$ (Alfa Aesar, 99.5\%) and $\mathrm{Sr}\left(\mathrm{NO}_{3}\right)_{2}$ (Alfa Aesar, 99.97\%) were dissolved separately in distilled water to form $0.1 \mathrm{M}$ solutions in the volumes required to obtain the final product stoichiometry. These solutions were stirred separately before combining and stirring further. A $0.2 \mathrm{M}$ citric acid solution was made using anhydrous citric acid (Alfa Aesar, $99.5 \%$ ) and added to the metal nitrate solution at a ratio of two moles of citric acid per mole of total metal ions. The resulting mixture was stirred for $12 \mathrm{~h}$. The mixture was heated in an oil bath to $80{ }^{\circ} \mathrm{C}$ and stirred until all the water had evaporated and a dry yellow foam had formed. The foam was calcined in air in a muffle furnace at $250{ }^{\circ} \mathrm{C}$ for $2 \mathrm{~h}$ then at $500{ }^{\circ} \mathrm{C}$ for $2 \mathrm{~h}$. Heating and cooling rates were $2.5^{\circ} \mathrm{C} \mathrm{min}-1$ and $5.0^{\circ} \mathrm{C} \mathrm{min}{ }^{-1}$, respectively. A yellow powder was obtained. The powder was milled at $400 \mathrm{rpm}$ for $1 \mathrm{~h}$ in a planetary ball mill. A $45 \mathrm{~mL}$ nylon grinding bowl with $10 \mathrm{~mm}$ zirconia grinding balls in a 1:10 powder to ball mass ratio was used.

X-ray Diffraction (XRD) analysis of the powder products was performed using a PANalytical Empyrean diffractometer (voltage: $45 \mathrm{kV}$; current: $40 \mathrm{~mA}$ ). The XRD patterns were recorded from $10^{\circ}$ to $100^{\circ}$ in $0.017^{\circ}$ steps over a $1 \mathrm{~h}$ period. A monochromated X-ray source emitting pure $K \alpha_{1}$ radiation was used. Rietveld refinement of the patterns was performed to confirm the structure and obtain the lattice parameters using HighScore Plus software from PANalytical. In addition, the Scherrer equation was used to calculate the average crystallite size.

Chemical analysis was performed by inductively coupled plasma mass spectrometry (ICP-MS) using an Agilent 7500ce. To prepare the material for ICP-MS analysis, samples of powder were dissolved in concentrated nitric acid by boiling for $24 \mathrm{~h}$ under reflux. Quantitative ICP-MS analysis of the concentrations of $\mathrm{Ce}, \mathrm{Sm}, \mathrm{Sr}, \mathrm{Si}$ and $\mathrm{Gd}$ were performed. A full, less accurate, scan of all elements was also performed to check for unknown impurities. XRF chemical analysis was also performed using a SPECTRO XEPOS spectrometer, looking specifically at the concentration of $\mathrm{Si}$.

The final microstructure of pellets sintered under different conditions was studied by SEM. Milled powders with all eight strontium contents from 0 to 4 cation $\%$ were pressed into $10 \mathrm{~mm}$ cylindrical pellets at $200 \mathrm{MPa}$ and sintered in a tube furnace in static air at $1250{ }^{\circ} \mathrm{C}, 1350{ }^{\circ} \mathrm{C}$ or $1450{ }^{\circ} \mathrm{C}$ for $4 \mathrm{~h}$. Samples were heated at $2{ }^{\circ} \mathrm{C} \mathrm{min}-1$ and cooled at $4{ }^{\circ} \mathrm{C} \mathrm{min}^{-1}$. The resulting pellets were polished to a mirror finish and thermally etched by heating for $1 \mathrm{~min}$ at a temperature $50{ }^{\circ} \mathrm{C}$ below the temperature at which they were sintered, using the same ramp rates. The samples were coated with gold using a Quorum Technologies Q150R sputter coater, and SEM images were obtained using a JEOL JSM-6700F SEM equipped with a field emission gun. For each sample, ImageJ software was used to measure the areas of at least 300 grains from SEM images of several different regions. Average grain areas and grain area distributions were obtained from these data.

For electrical measurements, impedance spectroscopy was performed on sintered pellets of five compositions, Sr00, Sr02, Sr05, Sr10 and Sr30. The pellets were made by pressing $4 \mathrm{~g}$ of powder at $200 \mathrm{MPa}$ in a $25 \mathrm{~mm}$ die. These were sintered at $1450{ }^{\circ} \mathrm{C}$ for $4 \mathrm{~h}$ and polished, both as described above. Pt electrodes of $12 \mathrm{~mm}$ diameter were deposited onto each face of the sintered pellets by screen-printing Pt ink (Engelhardt) and firing at $1000{ }^{\circ} \mathrm{C}$. Pt wires (Alfa-Aesar, 99.9\%) were attached to the electrodes. Samples were placed 
in a quartz reactor within a tube furnace and a flow of dried synthetic air $\left(50 \mathrm{~mL} \mathrm{~min}^{-1}\right)$ was established. Impedance spectra were obtained at temperatures from 150 to $800{ }^{\circ} \mathrm{C}$ at $50{ }^{\circ} \mathrm{C}$ intervals using a Solartron 1260 frequency response analyser. The amplitude of the applied AC voltage was $100 \mathrm{mV}$ and the frequency was swept from $10 \mathrm{MHz}$ to $0.1 \mathrm{~Hz}$. The spectra were fitted using the ZView software from Scribner Associates and values for the total, bulk and grain boundary conductivities were obtained.

The densities of pellets pressed and sintered at $1450{ }^{\circ} \mathrm{C}$ for $4 \mathrm{~h}$ as described above were determined from their mass and dimensions.

\section{Results}

\subsection{Synthesis}

The elemental concentrations of the main cations, determined by ICP-MS, for selected samples are shown in Table 1. The concentrations of Sm and Sr are within the nominal values; however, Ce is around 0.5 cation\% lower than expected. A small fraction of minor lanthanide elements was detected in all samples.

Table 1. Concentrations of the main cations and Gd, as determined by ICP-MS for selected samples of $\mathrm{Ce}_{0.8-\mathrm{x}} \mathrm{Sm}_{0.2} \mathrm{Sr}_{\mathrm{x}} \mathrm{O}_{2-\delta}$.

\begin{tabular}{cccccc}
\hline Sample & Ce (Cation\%) & Sm (Cation\%) & Sr (Cation\%) & Gd (Cation\%) & Total Minor Lanthanides (Cation\%) \\
\hline Sr00 & $79.1 \pm 1.3$ & $20.3 \pm 0.4$ & - & $0.47 \pm 0.02$ & 0.14 \\
Sr02 & $78.9 \pm 1.3$ & $20.4 \pm 0.3$ & $0.2 \pm 0.07$ & $0.46 \pm 0.003$ & 0.13 \\
Sr20 & $77.5 \pm 2.5$ & $20.0 \pm 0.6$ & $1.9 \pm 0.06$ & $0.45 \pm 0.02$ & 0.13 \\
Sr40 & $75.4 \pm 0.9$ & $20.2 \pm 0.4$ & $3.8 \pm 0.06$ & $0.44 \pm 0.006$ & 0.13 \\
\hline
\end{tabular}

Rietveld refinements of the XRD data showed all compositions had a single phase fluorite $F m-3 m$ crystal structure and the lattice parameter, $\boldsymbol{a}$, was found to increase linearly with increasing strontium content, as shown in Figure 1a. The average crystallite size of the powders was also estimated from the extent of peak broadening in the XRD patterns using the Scherrer equation. Figure $1 \mathrm{~b}$ shows that the values were in the range $6.5-11 \mathrm{~nm}$ and decreased with increasing strontium content in a roughly linear relationship. The densities of the pellets sintered at $1450{ }^{\circ} \mathrm{C}$ for $4 \mathrm{~h}$ were compared to the theoretical densities obtained from the XRD refinements to give the relative densities, which are plotted in Figure 1c. Relative density was found to increase with strontium content up to Sr10, after which it levelled off at $95-96 \%$.

\subsection{Microstructure}

A set of SEM images taken at the same magnification are presented Figure 2 to show the evolution of microstructure as a function of $\mathrm{Sr}$ content and sintering temperature. These show that porosity decreases, and grain size increases, with increasing sintering temperature and with increasing strontium content. The grain size distribution was found to be log-normal in all samples. A histogram of the distribution for Sr05 sintered at $1350{ }^{\circ} \mathrm{C}$ for $4 \mathrm{~h}$, which is typical of the samples studied, is shown in Figure 3. Figure 4 shows the average grain area as a function of strontium content for all three sintering temperatures. The average grain size for $\mathrm{Sr} 40$ was 14, 56 and 8 times greater than for Sr00 for sintering temperatures of $1250^{\circ} \mathrm{C}, 1350^{\circ} \mathrm{C}$ and $1450^{\circ} \mathrm{C}$, respectively. The relationship between grain area and strontium content is linear for the sintering temperature of $1250^{\circ} \mathrm{C}$ and partly linear for $1450{ }^{\circ} \mathrm{C}$. However, for $1350{ }^{\circ} \mathrm{C}$ there is a sharp increase in grain area between Sr02 and Sr10 giving rise to an S-shaped relationship. 


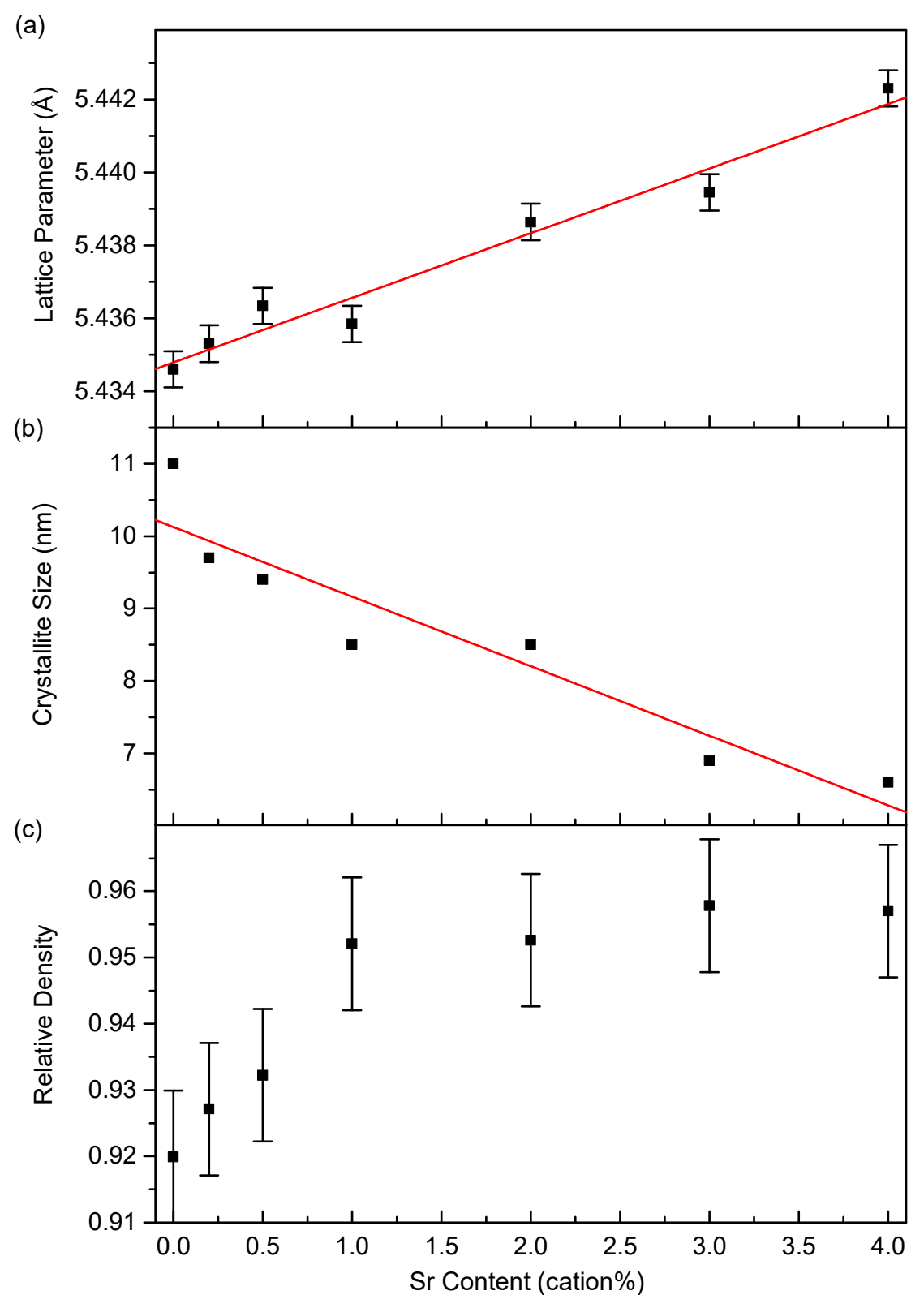

Figure 1. Plots against Sr content (x) of (a) lattice parameter, (b) average crystallite size, as calculated by the Scherrer equation, and (c) relative density of the $\mathrm{Ce}_{0.8-\mathrm{x}} \mathrm{Sm}_{0.2} \mathrm{Sr}_{\mathrm{x}} \mathrm{O}_{2-\delta}$ powders after sintering at $1450{ }^{\circ} \mathrm{C}$ for $4 \mathrm{~h}$.

\subsection{Electrical Properties}

The impedance spectra were fitted in order to obtain values for the total conductivity $\left(\sigma_{t}\right)$, and the contribution of the bulk $\left(\sigma_{b}\right)$ and grain boundary $\left(\sigma_{g b}\right)$ processes to the total conductivity of the samples Sr00, Sr02, Sr05, Sr10 and Sr30 sintered at $1450{ }^{\circ} \mathrm{C}$ for $4 \mathrm{~h}$. In the atmosphere of dry synthetic air and at the measurement temperatures used here, it is known that samarium-doped ceria samples are essentially pure oxygen ion conductors, and therefore that $\sigma_{t}, \sigma_{b}$, and $\sigma_{g b}$ relate to the oxygen ion conductivity of the samples [26]. Figure 5 shows a Nyquist plot of the impedance spectra obtained at $250{ }^{\circ} \mathrm{C}$ for all samples. The larger, higher frequency arc is attributed to bulk processes and the smaller, lower frequency arc to processes taking place at the grain boundaries. The spectra were fitted by modelling the bulk and grain boundary processes as two sub-circuits in series, each consisting of a resistor and constant phase element in parallel. Due to inductance effects, the bulk and grain boundary resistances can only both be reliably determined at measurement 
temperatures of $350{ }^{\circ} \mathrm{C}$ or below. At higher temperatures, therefore, the total resistance was determined from the intercept of the impedance plot with the $x$-axis.

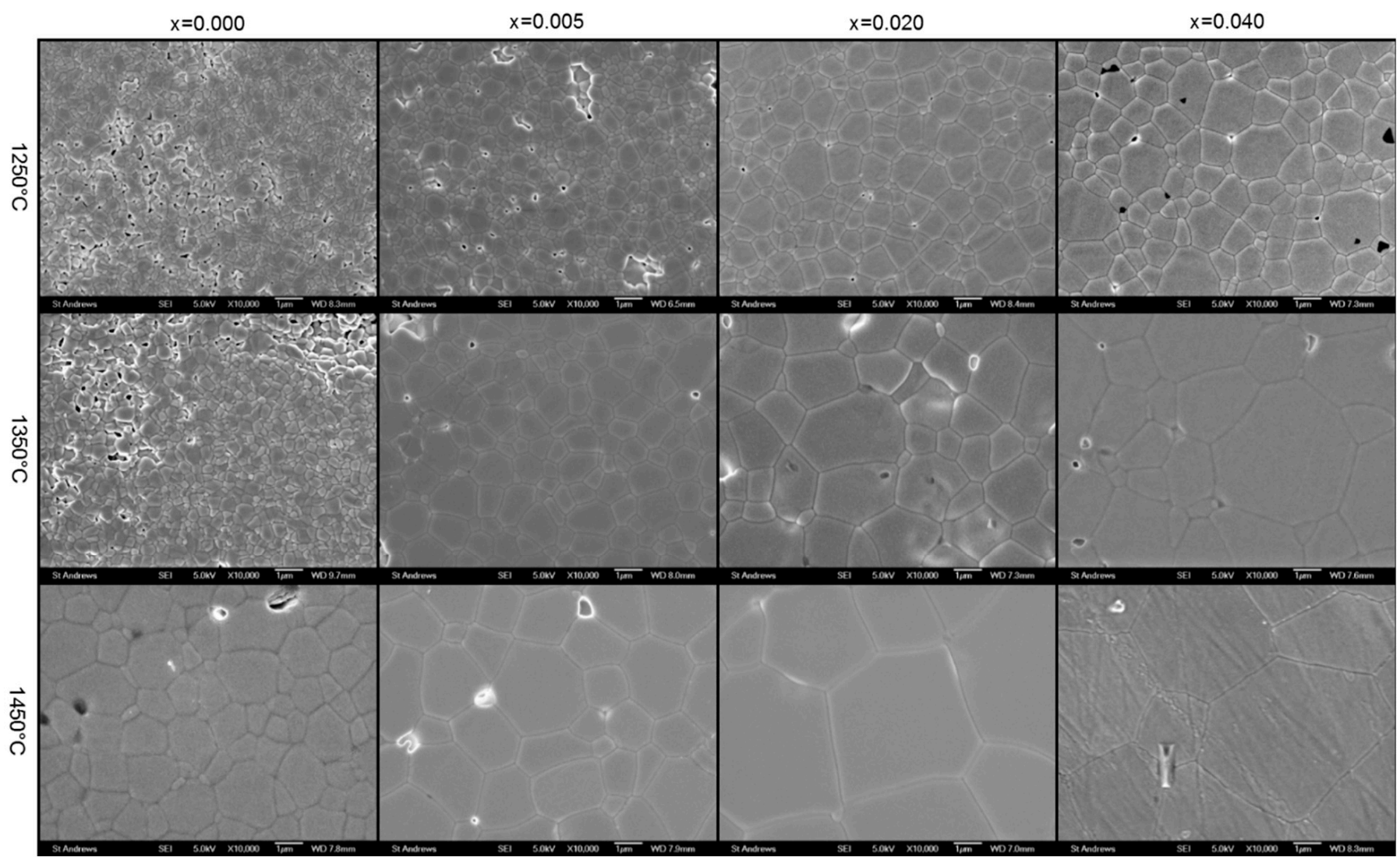

Figure 2. SEM micrographs of sintered and thermally etched samples of Sr00, Sr05, Sr20 and Sr40 ( $x=0,0.005,0.020,0.040$, respectively, in $\mathrm{Ce}_{0.8-\mathrm{x}} \mathrm{Sm}_{0.2} \mathrm{Sr}_{\mathrm{x}} \mathrm{O}_{2-\delta}$ ) sintered at $1250{ }^{\circ} \mathrm{C}, 1350{ }^{\circ} \mathrm{C}$ and $1450{ }^{\circ} \mathrm{C}$ for $4 \mathrm{~h}$, as indicated.

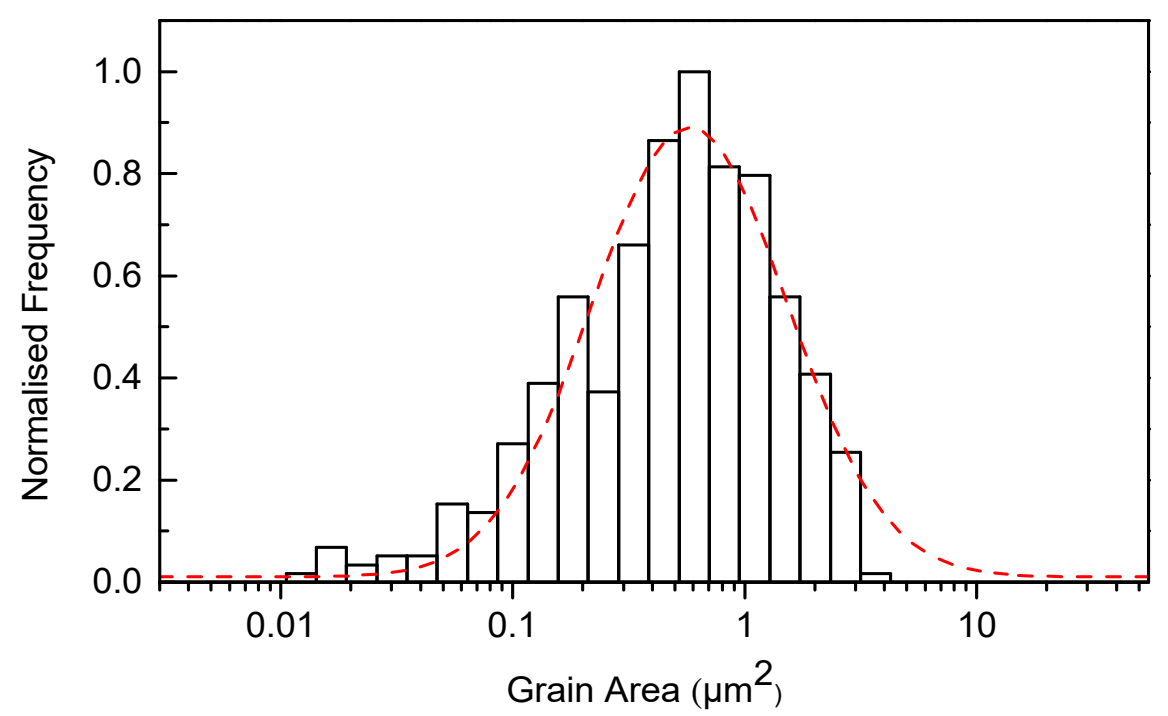

Figure 3. Log histogram of normalised frequency against grain area for $\mathrm{Sr} 05$ sintered at $1350{ }^{\circ} \mathrm{C}$ for $4 \mathrm{~h}$. Red dashed line shows a log normal fit. 
(a)

(b)

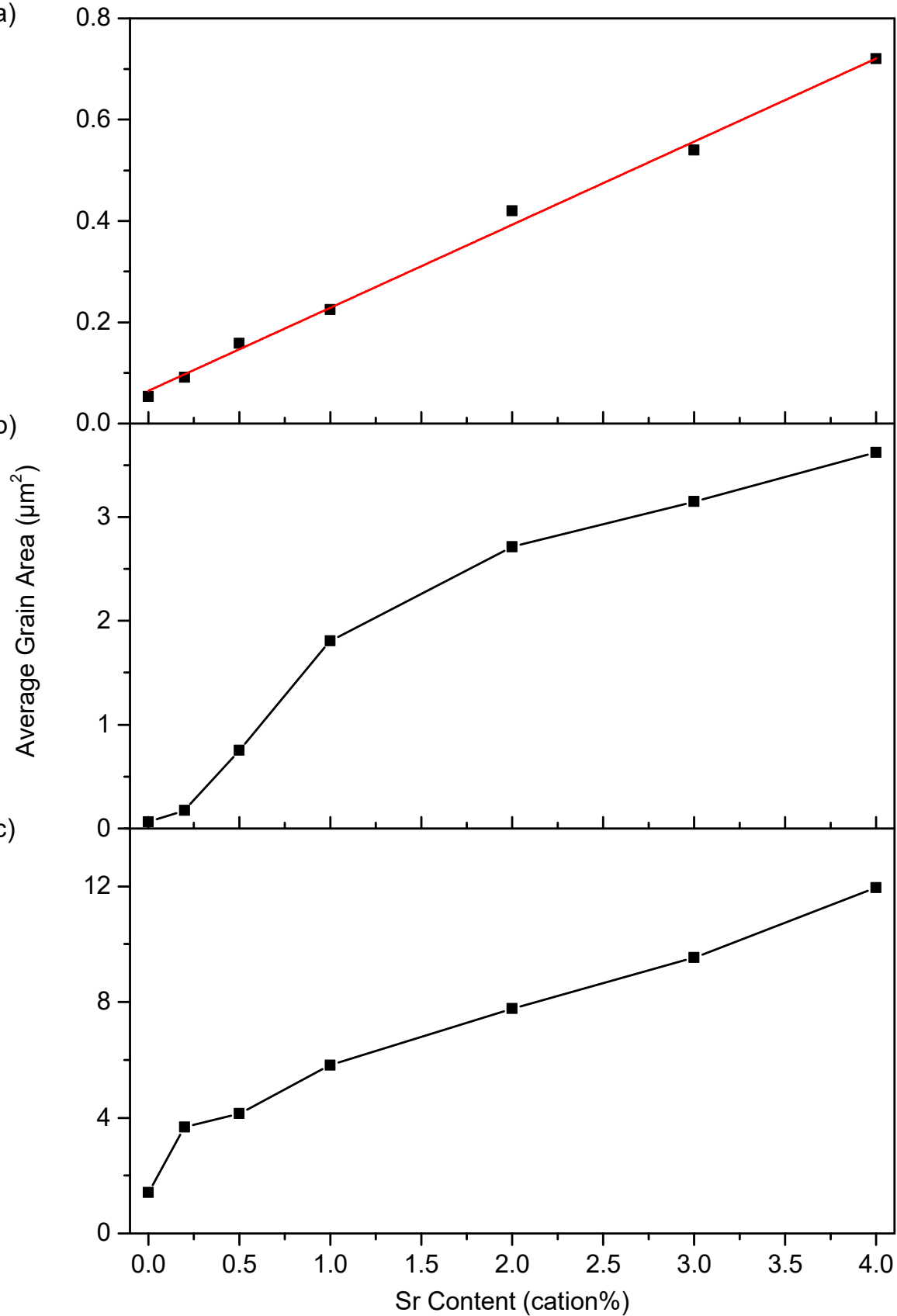

Figure 4. Plots of average cross-sectional grain area against $\mathrm{Sr}$ content for all $\mathrm{Ce}_{0.8-x} \mathrm{Sm}_{0.2} \mathrm{Sr}_{x} \mathrm{O}_{2-\delta}$ samples sintered for $4 \mathrm{~h}$ at (a) $1250{ }^{\circ} \mathrm{C}$, (b) $1350{ }^{\circ} \mathrm{C}$ and (c) $1450{ }^{\circ} \mathrm{C}$. Plot (a) shows a linear fit of the data, and plots $(\mathbf{b}, \mathbf{c})$ show a joining line as a guide to the eye.

Conductivity is empirically found to vary with temperature according to the exponential relationship,

$$
\sigma=\frac{\sigma_{o}}{T} e^{-\frac{E_{a}}{k T}}
$$

where $\sigma$ is the conductivity, $T$ is the sample temperature, $k$ is the Boltzmann constant, $\sigma_{0}$ is a pre-exponential constant and $E_{\boldsymbol{a}}$ is the activation energy for conductivity. The total activation energy, $E_{a}$, is usually considered to be composed of an activation energy for oxygen ion migration, $\boldsymbol{E}_{m}$, and an activation energy for the dissociation of defect associates, $E_{\text {ass }}$ [27]. Figure 6 shows Arrhenius plots of the total, bulk and grain boundary conductivities for Sr00. For total conductivity, the relationship is linear, obeying Equation (1), at 
lower temperatures, but deviates at higher temperatures. Figures 7 and 8 show that this behaviour was observed for all samples.
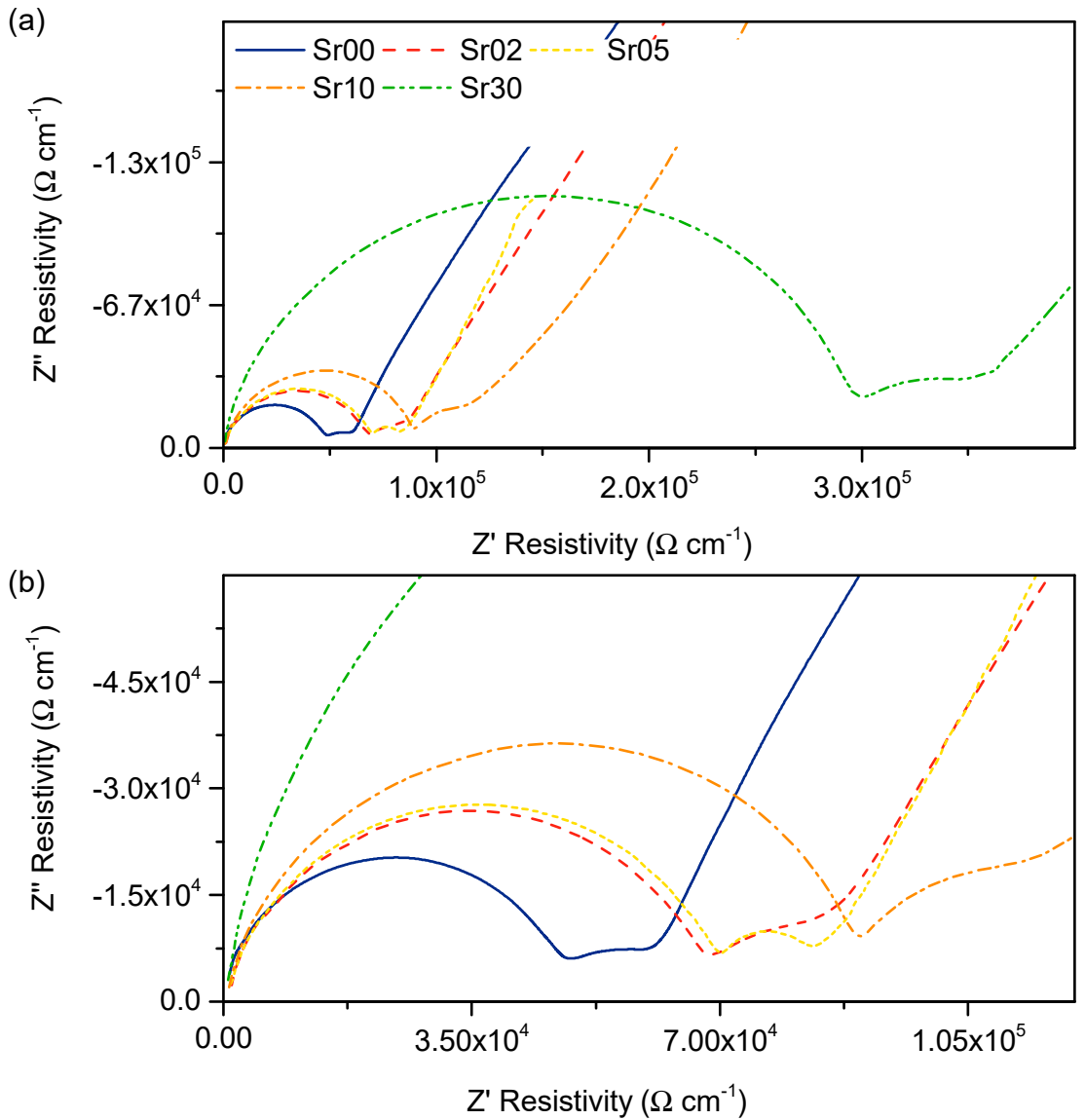

Figure 5. Complete Nyquist plot (a) and detail (b) showing impedance spectra for $\mathrm{Ce}_{0.8-\mathrm{x}} \mathrm{Sm}_{0.2} \mathrm{Sr}_{\mathrm{x}} \mathrm{O}_{2-\delta}$ samples indicated measured at $250{ }^{\circ} \mathrm{C}$. Data are plotted as resistivities to normalise for variations in sample dimensions.

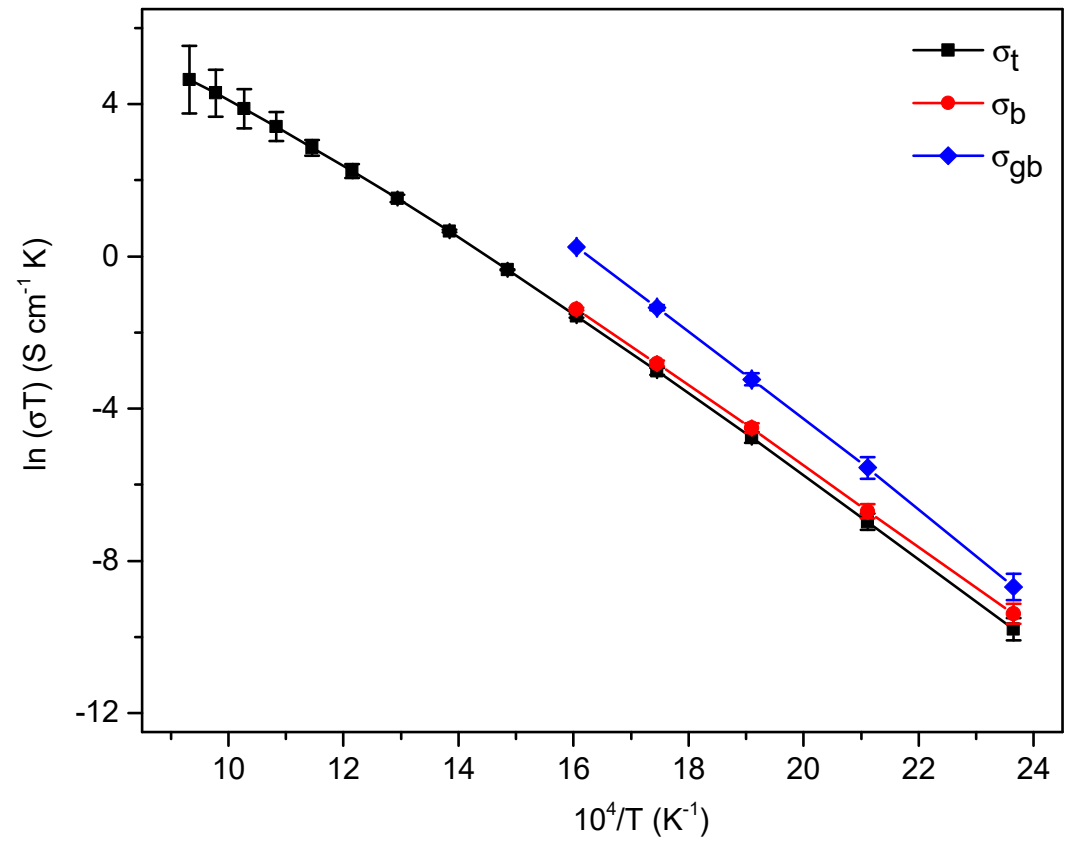

Figure 6. Arrhenius plots of total, bulk and grain boundary conductivity for Sr00. 


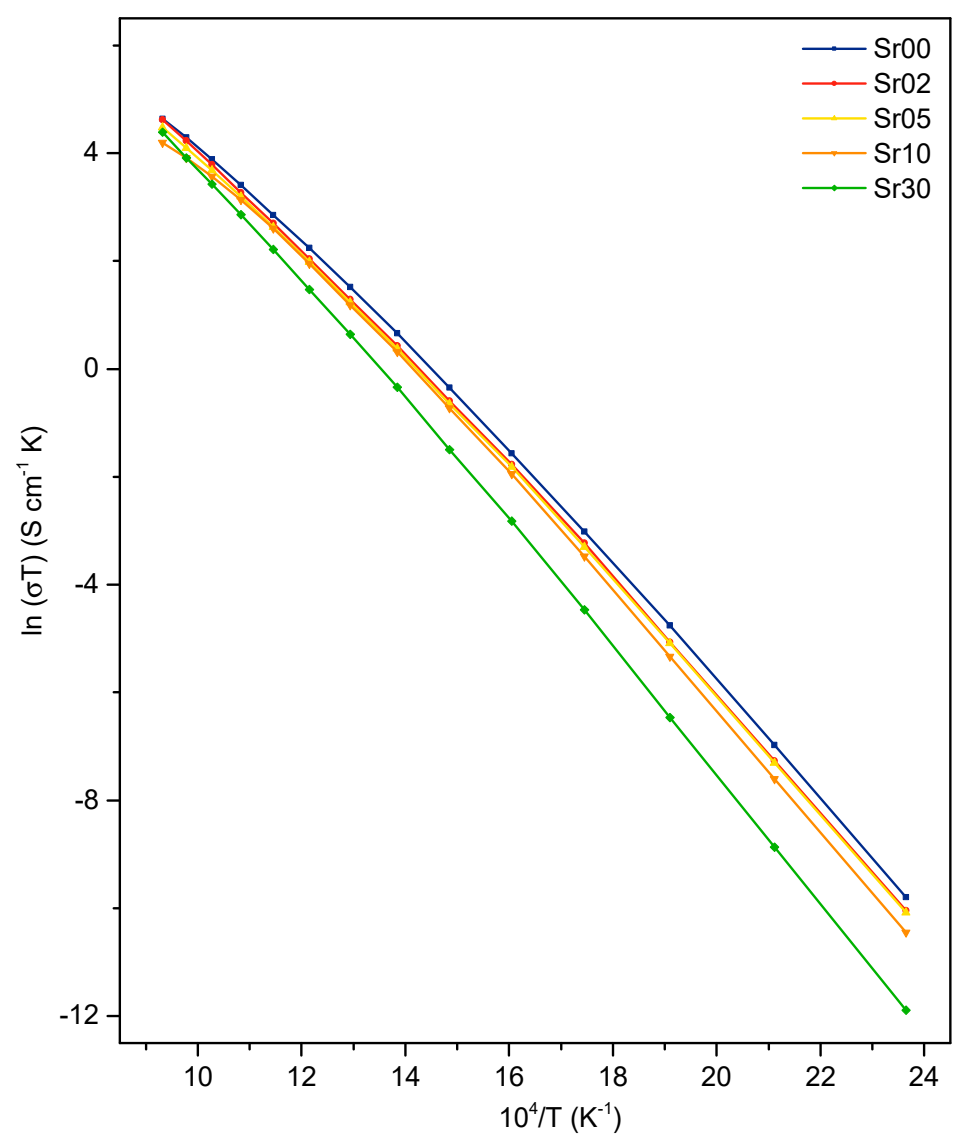

Figure 7. Arrhenius plot of total conductivity of the $\mathrm{Ce}_{0.8-\mathrm{x}} \mathrm{Sm}_{0.2} \mathrm{Sr}_{\mathrm{x}} \mathrm{O}_{2-\delta}$ samples indicated as a function of temperature from $150{ }^{\circ} \mathrm{C}$ to $800^{\circ} \mathrm{C}$.

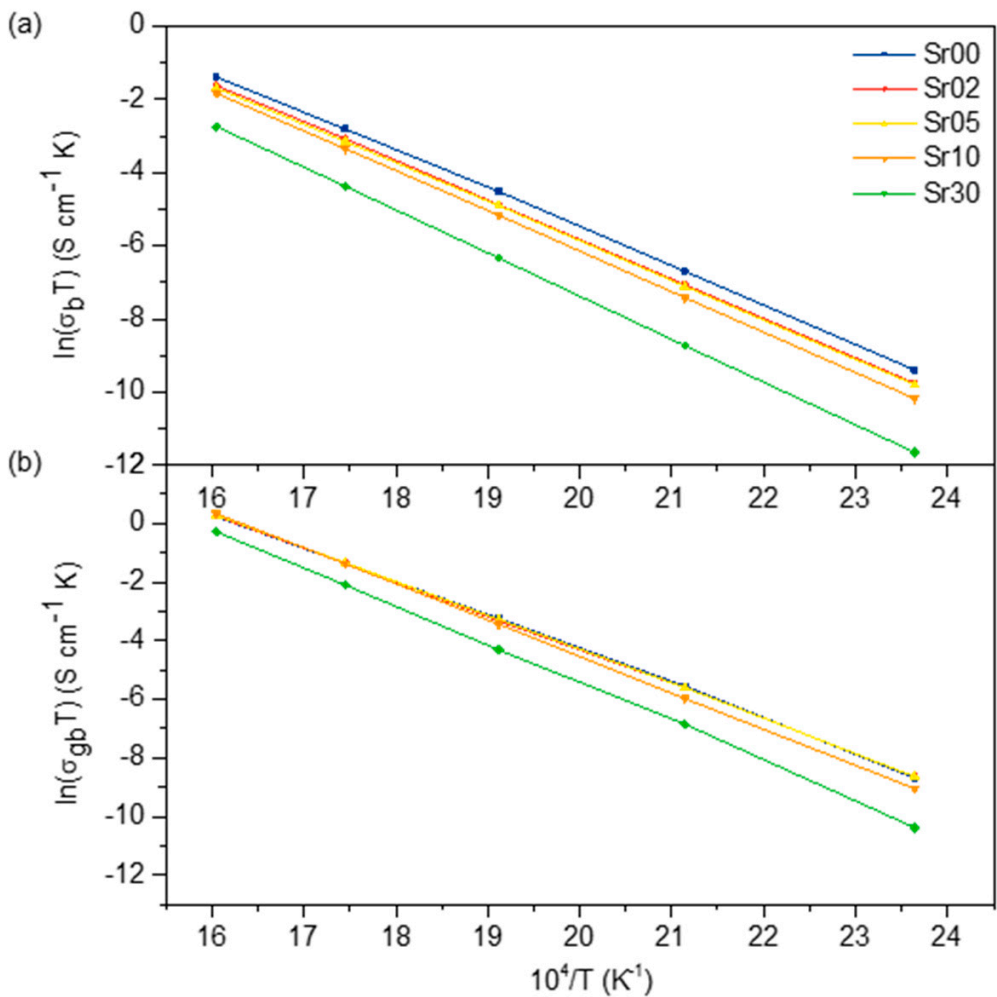

Figure 8. Arrhenius plots of (a) bulk and (b) grain boundary components of conductivity for the samples indicated. 
From Equation (1), it is clear that $E_{a}$ can be calculated from the slope of an Arrhenius plot of conductivity. It is also possible to obtain values for $\boldsymbol{E}_{a s s}$ and $\boldsymbol{E}_{m}$ by assuming that no defect associates exist at high temperatures (having been thermally dissociated) so that the slope at higher temperatures is determined solely by $\boldsymbol{E}_{m} . \boldsymbol{E}_{\text {ass }}$ can then be calculated as $E_{a s s}=E_{a}-E_{m}$, using the slope of the lower temperature section of the plot to find $E_{a}$. In the present work, however, the gradient at high temperatures was too variable to reliably calculate $\boldsymbol{E}_{\boldsymbol{m}}$ and $\boldsymbol{E}_{\boldsymbol{a s s}}$. Nevertheless, values for $\boldsymbol{E}_{\boldsymbol{a}}$ were calculated for the total, bulk and grain boundary conductivity using the temperature range $150-350{ }^{\circ} \mathrm{C}$. Figure 9 shows the variation of $\boldsymbol{E}_{\boldsymbol{a}}$ with strontium content. It shows that the grain boundary $\boldsymbol{E}_{\boldsymbol{a}}$ is higher than the bulk $E_{\boldsymbol{a}}$ and that there is a general increase in all three activation energies with increasing strontium content. Activation energy for total conductivity increased from $0.94 \mathrm{eV}$ to $1.03 \mathrm{eV}$ from $\mathrm{Sr} 00$ to $\mathrm{Sr} 30$. There is an interesting variation, however, in the grain boundary $E_{a}$ which passes through a minimum at a strontium content of 0.2 cation $\%$.

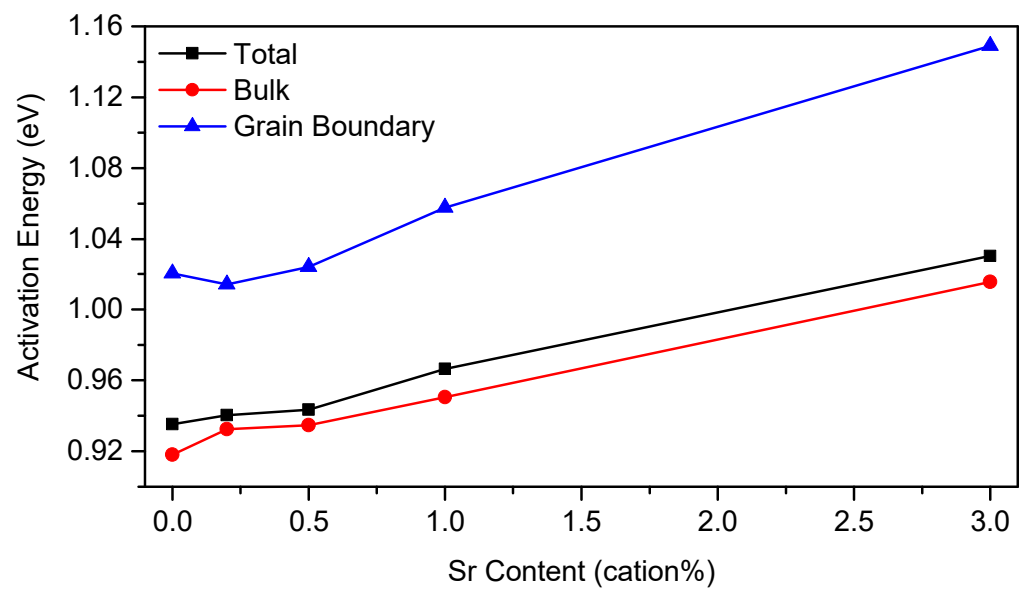

Figure 9. Plots of activation energy as a function of $\mathrm{Sr}$ content for total, bulk and grain boundary ionic conductivity of $\mathrm{Ce}_{0.8-\mathrm{x}} \mathrm{Sm}_{0.2} \mathrm{Sr}_{\mathrm{x}} \mathrm{O}_{2-\delta}$ samples.

In order to compare conductivity data for all samples over the whole temperature range, it is convenient to normalise the conductivities with respect to those of the undoped sample (Sr00). The normalised conductivity is the conductivity of the sample at each temperature divided by that of Sr00 at the same temperature. Figure 10 shows the normalised total, bulk and grain boundary conductivities for all samples. From Figure 10a, it is clear that $\mathrm{Sr} 00$ is the most conductive sample at temperatures above $600{ }^{\circ} \mathrm{C}$; however, the magnitude of the error in the conductivity exceeds the magnitude of the difference between the samples. It is also apparent that the rate of increase in total conductivity with temperature increases with increasing strontium content (as can also be deduced from the values for $\boldsymbol{E}_{\boldsymbol{a}} \mathrm{s}$ in Figure 9). Therefore, the biggest change in normalised conductivity is for $\mathrm{Sr} 30$, in which it increased from 0.1 to 0.8 times that of Sr00 from $150{ }^{\circ} \mathrm{C}$ to $800{ }^{\circ} \mathrm{C}$. Figure $10 \mathrm{~b}, \mathrm{c}$ show the normalised bulk and grain boundary conductivities up to $350^{\circ} \mathrm{C}$. The trends for normalised bulk conductivity are similar to those for normalised total conductivity (though not as pronounced due to the smaller temperature range). The behaviour for grain boundary conductivity is slightly different, however. Sr02 and Sr05 show similar conductivity to Sr00 across the temperature range whilst $\mathrm{Sr} 10$ and Sr30 increase substantially over the relatively small $200^{\circ} \mathrm{C}$ temperature range. 
(a)

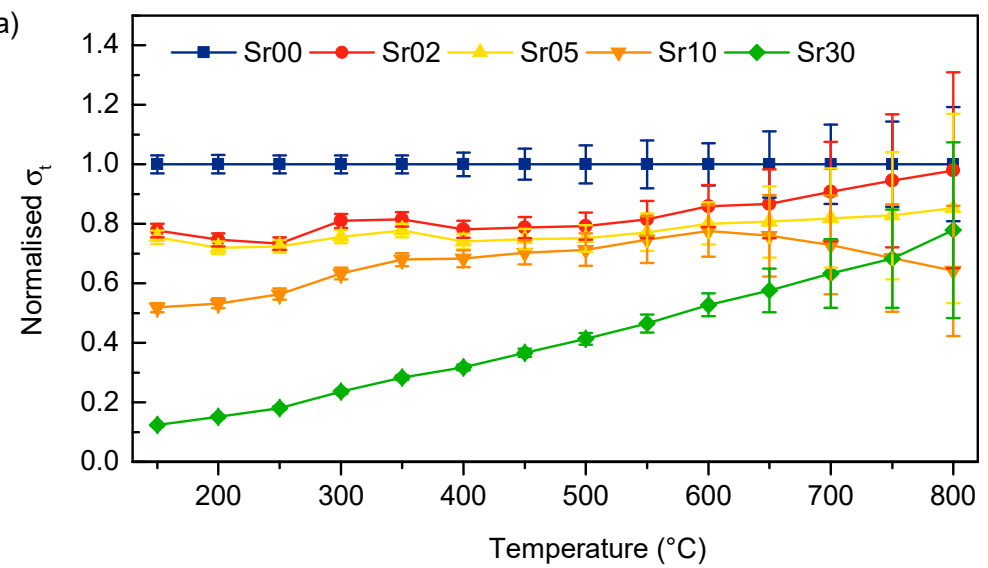

(b)

(c)

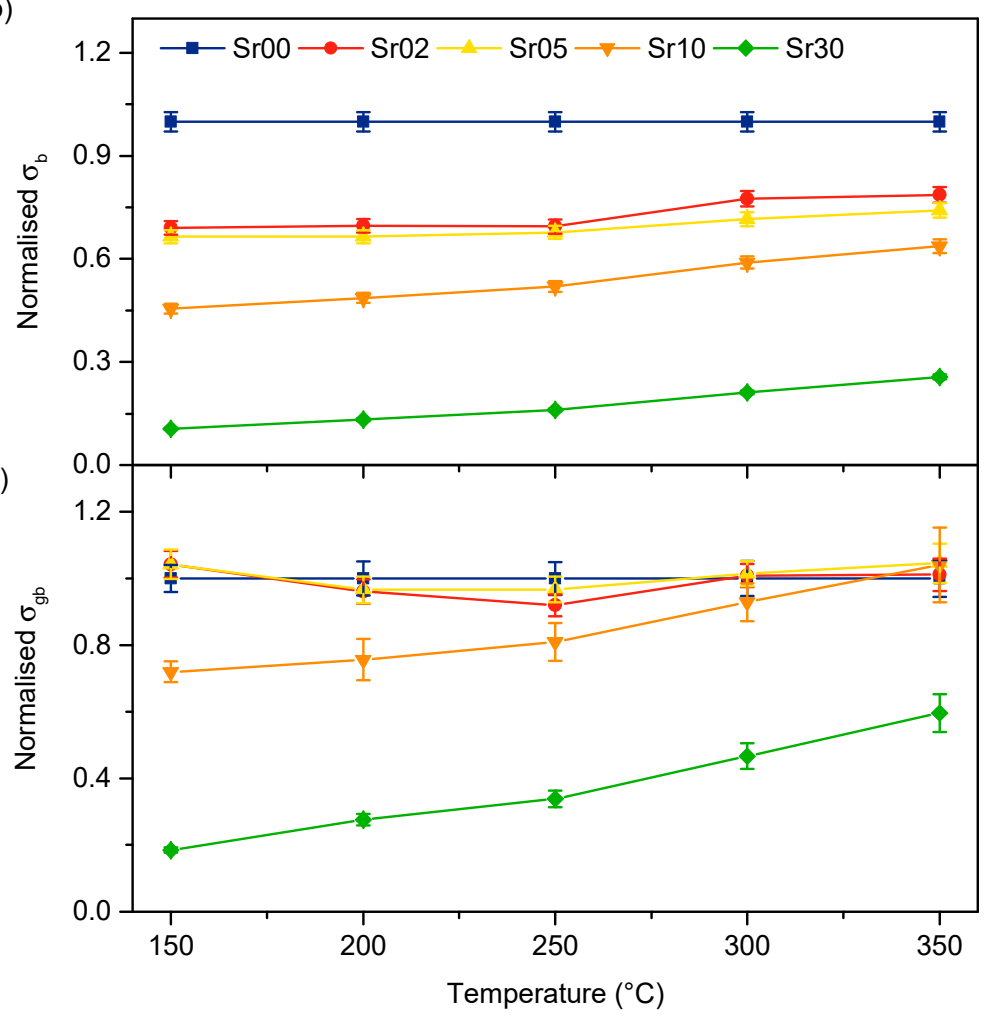

Figure 10. Normalised (a) total, (b) bulk and (c) grain boundary conductivity for the $\mathrm{Ce}_{0.8-\mathrm{x}} \mathrm{Sm}_{0.2} \mathrm{Sr}_{\mathrm{x}} \mathrm{O}_{2-\delta}$ samples indicated. Conductivity was normalised by dividing by the conductivity of the undoped sample (Sr00) at each temperature.

In order to see the trend in conductivity with strontium content more clearly, Figure 11 shows the variation in the total, bulk and grain boundary conductivity at a single temperature, $300{ }^{\circ} \mathrm{C}$. Here, the absolute values of conductivity can be compared as the range is not so large. A clear trend can be seen, which is similar for the total and bulk, and slightly different for the grain boundary conductivity. Both the total and bulk conductivity show a roughly linear decrease in conductivity with increasing strontium content from $\mathrm{Sr02}$ to Sr30, with a larger decrease from the undoped sample, Sr00, to the first doped sample, Sr02. The total decreases in the total and bulk conductivity across the full range are very similar at $76 \%$ and $79 \%$, respectively. The grain boundary conductivity shows a different trend. There is a slight increase from Sr00 to Sr005 followed by a linear decrease to Sr30. The increase in grain boundary conductivity from $\mathrm{SrO0}$ to the maximum at $\mathrm{Sr005}$ is $8 \%$ while the decrease from Sr00 to Sr30 was 54\%. 
(a)

(b)

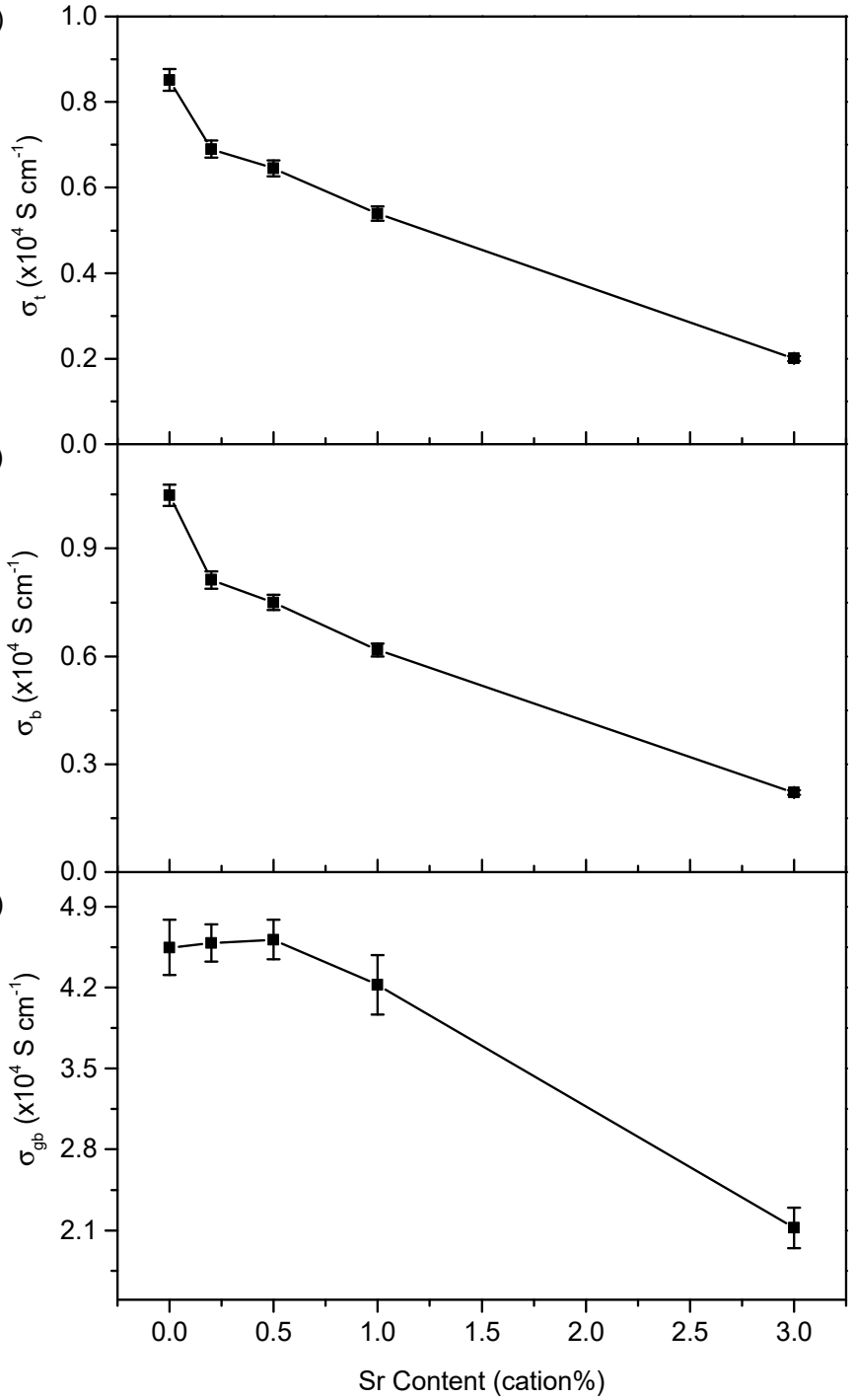

Figure 11. Plots of the variation of (a) total, (b) bulk and (c) grain boundary conductivities with $\mathrm{Sr}$ content for all $\mathrm{Ce}_{0.8-} \mathrm{Sm}_{0.2} \mathrm{Sr}_{\mathrm{x}} \mathrm{O}_{2-\delta}$ samples measured at $300{ }^{\circ} \mathrm{C}$.

It is useful to examine the relative contributions to the total conductivity of the bulk and grain boundary components. For example, the $24 \%$ decrease in the total conductivity of Sr05 compared to Sr00 at $300{ }^{\circ} \mathrm{C}$ results from an $28 \%$ decrease in bulk conductivity and a $2 \%$ increase in grain boundary conductivity, whilst the $76 \%$ decrease for $\mathrm{Sr} 30$ results from a $79 \%$ decrease in the bulk and a $53 \%$ decrease in the grain boundary conductivity. It is a general trend that the relative contribution of the grain boundary to the total conductivity increases with increasing strontium content. This relationship between the total conductivity and the bulk and grain boundary components of conductivity is best described by the blocking factor, $\boldsymbol{B F}$, which is defined as the resistance due to the grain boundaries, $\boldsymbol{R}_{g b}$, divided by that due to the bulk, $\boldsymbol{R}_{\boldsymbol{b}}$, as shown in Equation (2).

$$
B F=\frac{R_{g b}}{R_{b}}
$$

Figure 12a shows a plot of the blocking factor against strontium content. At all measured temperatures it shows a large decrease in the blocking factor between the undoped sample (Sr00) and the doped samples (Sr02-Sr30), then a linear decrease with increasing strontium content. The size of the initial drop decreases with increasing temperature and the slope of the decrease from $\mathrm{Sr} 02$ to $\mathrm{Sr} 30$ is similar for all temperatures. (The data for $150{ }^{\circ} \mathrm{C}$ are not included here because, at such a low temperature, the low frequency 
intercept of the grain boundary arc was not included in the corresponding Nyquist spectra, and so the fit was not considered good enough to allow calculation of reliable BF values).

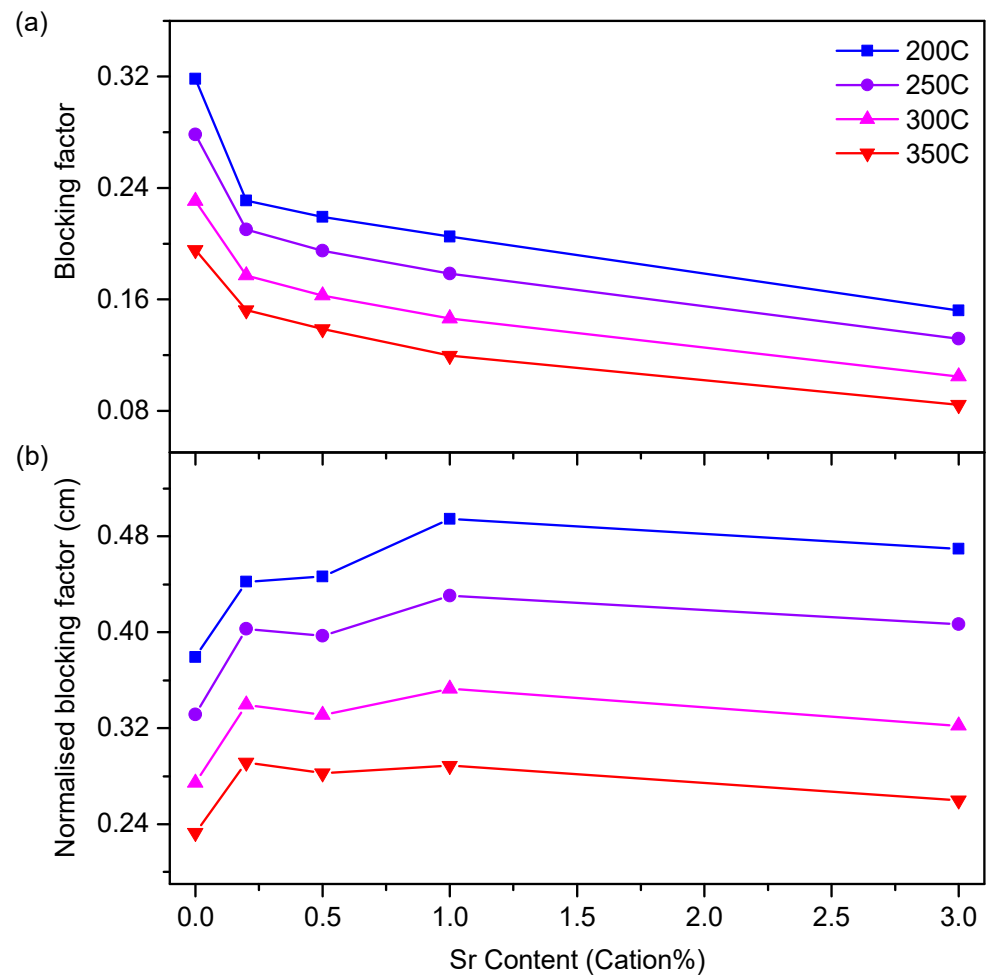

Figure 12. Plots of (a) blocking factor and (b) normalised blocking factor against strontium content for measurement temperatures from $200{ }^{\circ} \mathrm{C}$ to $350{ }^{\circ} \mathrm{C}$.

It is possible to semi-quantitatively describe the effect of grain size on the blocking factor. This allows the factors affecting grain boundary conductivity to be examined in more detail. Assuming that the magnitude of the blocking factor is directly proportional to the number of grain boundaries per unit length in the sample, it is possible to get a value for $B F$ normalised for grain size, NBF. As the number of grain boundaries per unit length, $\rho_{g b}$, is inversely proportional to grain diameter then $\rho_{g b}$ is related to grain area, $G_{A}$, as shown in Equation (3).

$$
\rho_{g b} \propto \frac{1}{\sqrt{G_{A}}}
$$

It is then possible to define the normalised blocking factor as the blocking factor divided by $\rho_{g b}$ as shown in Equation (4).

$$
N B F=\frac{B F}{\rho_{g b}}
$$

Values for the normalised blocking factor are plotted in Figure 12b. As with the blocking factor, there is a step between the undoped material ( $\mathrm{SrO0}$ ) and the doped materials (Sr02-Sr03) followed by a linear trend. However, the step is now reduced in size and the linear region is almost flat.

Finally, to evaluate these materials as candidates for SOFC electrolytes, the total conductivity at realistic operating temperatures should be considered. Figure 13 shows the variation of total conductivity with strontium content at $500{ }^{\circ} \mathrm{C}, 600{ }^{\circ} \mathrm{C}$ and $700{ }^{\circ} \mathrm{C}$. The trends are similar to those at $250{ }^{\circ} \mathrm{C}$, shown in Figure 11, with a linear decrease in conductivity with strontium content. It is apparent from the plot that the relative decrease in conductivity with increasing strontium content is reduced as temperature increases. The decreases from Sr00 to Sr30 at $500{ }^{\circ} \mathrm{C}, 600{ }^{\circ} \mathrm{C}$ and $700{ }^{\circ} \mathrm{C}$ were $47 \%, 37 \%$ and $22 \%$, respectively. 


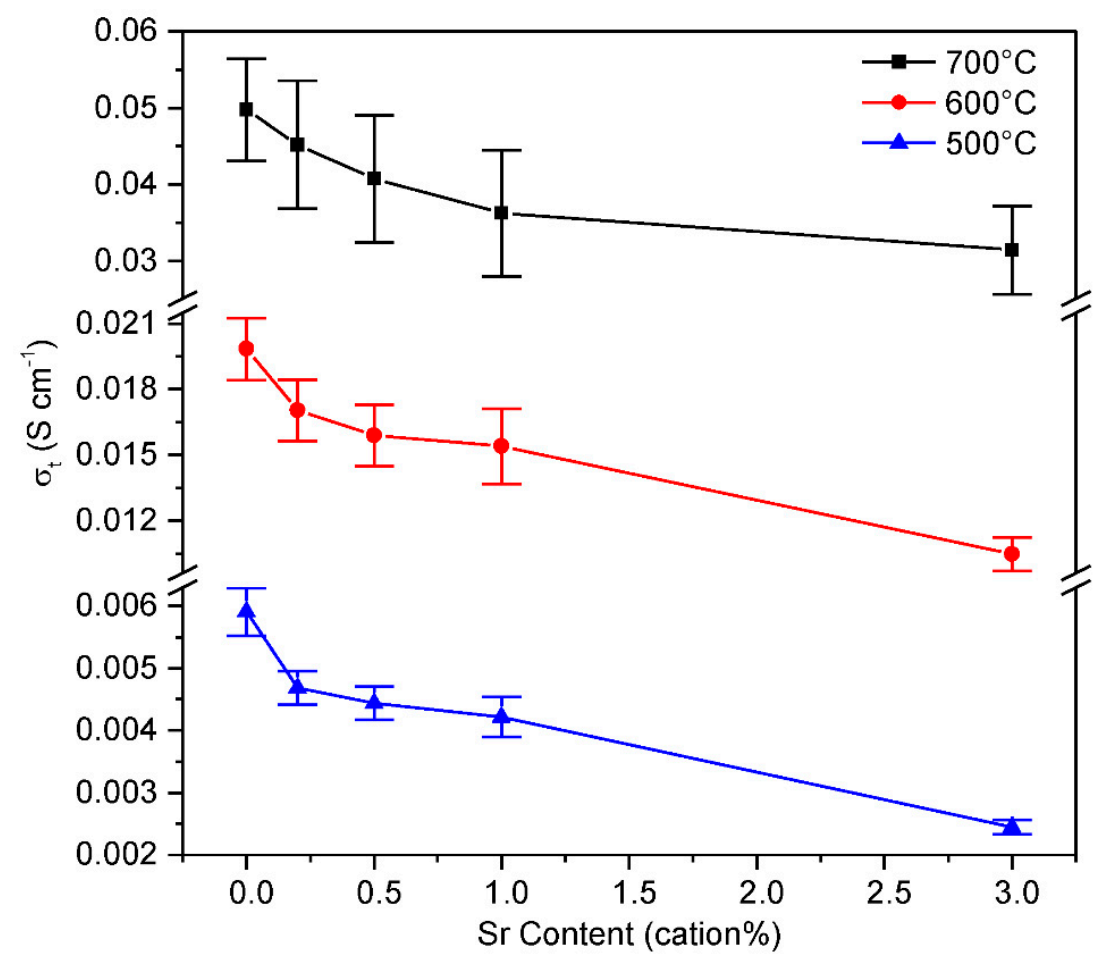

Figure 13. Plot of total conductivity measured at $500{ }^{\circ} \mathrm{C}, 600{ }^{\circ} \mathrm{C}$ and $700{ }^{\circ} \mathrm{C}$ as a function of $\mathrm{Sr}$ content for all $\mathrm{Ce}_{0.8-\mathrm{x}} \mathrm{Sm}_{0.2} \mathrm{Sr}_{\mathrm{x}} \mathrm{O}_{2-\delta}$ samples.

\section{Discussion}

\subsection{Synthesis}

The composition of the synthesised powders was checked by ICP-MS analysis. Table 1 shows that the concentrations of $\mathrm{Sm}$ and $\mathrm{Sr}$ are within the nominal values; however, that of Ce is lower than expected. The decreased Ce concentration is approximately equal to the concentration of the Gd impurity. This suggests that $\mathrm{Gd}$ was introduced as an impurity in the cerium nitrate. The concentration of impurities found in the powders are within the specified purities of the metal nitrates used in the synthesis: $99.5 \%$ for the cerium nitrate hexahydrate and $99.9 \%$ for the samarium nitrate hexahydrate. Impurities like the minor lanthanide impurities are likely to be present in most doped ceria electrolytes, as reagents of $99.9 \%$ purity are among the most commonly used. The concentration of the Gd impurity, however, is high enough that it may have a small, but significant, effect on the material properties. A commonly used reagent is $99.5 \%$ cerium nitrate hexahydrate [5-7]; however, it is not known if the Gd impurity is present in such materials, as elemental analysis is not usually carried out. There is no appreciable systematic difference between materials synthesised with $99.5 \%$ or $99.9 \%$ pure reagents in the literature, though differences would likely be obscured by other larger differences between the materials.

Examination of previous studies on strontium doping indicated that strontium should be fully soluble in $\mathrm{Ce}_{0.8} \mathrm{Sm}_{0.2} \mathrm{O}_{2-\delta}$ at the synthesised levels of doping. The linear variation in XRD lattice parameter and retention of a single phase Fm-3m crystal structure confirmed this. The values for the crystallite size were in the range expected from previous work using the same synthesis method [25]. The decrease in the crystallite size of the powder with increasing strontium content is, however, in contrast to the increases in density and grain size in the final sintered materials. The crystallite size of the powder is determined by the conditions of the sol-gel synthesis and subsequent calcination. There are two other reports of the relationship between strontium doping and crystallite size of codoped ceria. These studies looked at the $\mathrm{Ce}_{0.8+x} \mathrm{Sm}_{0.2-2 \mathrm{x}} \mathrm{Sr}_{\mathrm{x}} \mathrm{O}_{2-\delta}$ [22] $(\mathrm{x}=0-0.06)$ and $\mathrm{Ce}_{0.9} \mathrm{Mg}_{0.1-\mathrm{x}} \mathrm{Sr}_{\mathrm{x}} \mathrm{O}_{1.9}$ [21] ( $\left.\mathrm{x}=0-0.06\right)$. Both showed slight variation in crystallite size, but no overall trend, suggesting that there was no direct relationship to the strontium content. These two systems vary from the one in this study, however, in that their oxygen vacancy 
concentrations were kept constant as strontium content was changed. In addition, it has also been observed previously that crystallite size decreased from $11 \mathrm{~nm}$ to $8 \mathrm{~nm}$ when the samarium content of $\mathrm{Ce}_{1-x} \mathrm{Sm}_{\mathrm{x}} \mathrm{O}_{2-\delta}$ was increased from $\mathrm{x}=0.1$ to $\mathrm{x}=0.3$ in materials made under the same conditions as used in the present study, and that crystallite size was strongly affected by the calcination conditions [25]. In this system oxygen vacancy concentration did increase. There is a possible mechanism by which an increase in oxygen vacancy concentration could cause a drop in cation diffusivity, inhibiting crystallite growth during calcination. Chen et al. [28] proposed that the rate-limiting diffusion step in aliovalently doped ceria is interstitial cation diffusion through oxygen vacancies and that this process can be hindered by the association of vacancies with other species. It is also known that as the concentration of dopants and vacancies increases, there is a greater tendency for these associates to form [29,30]. It follows that the parallel increase in vacancy and $\mathrm{Sr}$ concentration in the $\mathrm{Ce}_{0.8-} \mathrm{Sm}_{0.2} \mathrm{Sr}_{\mathrm{x}} \mathrm{O}_{2-\delta}$ materials studied here could reduce cation diffusion, and therefore slow crystallite growth at the intermediate temperatures used for their synthesis and calcination. It should be noted that this effect does not contradict the observed improvements in sintering and grain growth with increasing Sr content, since associated defects are thought to be mostly absent by $1000{ }^{\circ} \mathrm{C}$ [31].

The increase in the final density of the sample with increasing strontium content is a clear sign of an improved rate of sintering. As was mentioned in the Introduction, almost all studies on strontium co-doping showed that sinterability was improved with strontium addition. The exception is a study on $\mathrm{Ce}_{0.8+x} \mathrm{Sm}_{0.2-2 \mathrm{x}} \mathrm{Sr}_{\mathrm{x}} \mathrm{O}_{2-\delta}$ by Jaiswal et al. [22], which does not show a clear trend, but does suggest a decrease. The observation of a plateau in density at strontium doping levels of more than $1 \mathrm{~mol} \%$ is in agreement with Zheng et al., who also found improvements in density were negligible above this level of strontium in $\mathrm{Ce}_{0.8} \mathrm{Sm}_{0.2} \mathrm{O}_{2-\delta}$ [15]. Only two previous studies give a mechanism for the improvement in sintering. Zheng et al. [15] suggest that viscous flow could be occurring during sintering, though they do not provide any details, whilst Lane et al. [10] point out the possibility of liquid phase sintering by the formation of a strontia-silica phase which is liquid at sintering temperatures. Neither mechanism is proven, however. Sintering is ultimately governed by diffusion, so improvements must result from an enhancement in diffusion. Possible mechanisms for diffusion enhancement are discussed in relation to grain growth in the next section.

\subsection{Microstructure}

Like the improvements in sintering, the increase in grain size with strontium content was expected. Other work on the relationship between grain size and strontium doping has not studied as many compositions and sintering temperatures, however. The log-normal distribution of grain size, shown in Figure 3, indicated that grain growth was normal in all samples [32]. The trends in grain size with strontium content and sintering temperature give a detailed description of the progression of grain size. These trends, in particular the step in grain size when sintering at $1350{ }^{\circ} \mathrm{C}$, can be explained by features of the sintering process. There are two distinct stages of sintering: densification and pore elimination; and grain growth. Until pores are eliminated from the material, they pin grain boundaries, greatly slowing grain growth. The samples sintered at $1350{ }^{\circ} \mathrm{C}$ show this transition. Below $0.5 \%$ doping grain growth is in the slow, densification and pore elimination stage, but above $1 \%$ doping samples are in the fast grain growth stage. The two differing rates of grain growth are why a 56 fold difference in grain area is seen between high and low strontium samples sintered at $1350{ }^{\circ} \mathrm{C}$. By contrast, samples sintered at $1250{ }^{\circ} \mathrm{C}$ appear all to be in the slow grain growth regime and samples sintered at $1450{ }^{\circ} \mathrm{C}$ to all be in the fast grain growth regime, and therefore each shows a linear relationship between grain area and strontium content. It might be expected that samples sintered at $1450{ }^{\circ} \mathrm{C}$ would not show a completely linear increase with strontium content as there could still be a change in growth regime, but at lower strontium content than was seen at $1350{ }^{\circ} \mathrm{C}$. In fact, it can be seen in Figure $4 \mathrm{c}$ that the grain size is indeed depressed somewhat at the lowest strontium content. 
As with the sintering improvements, faster grain growth is a result of improved diffusion. It is likely that the mechanism for this improvement is the same for sintering and grain growth. Let us consider first the suggestions of Lane et al. and Zheng et al., that liquid phase sintering or viscous flow occurs. It might be expected that if strontium introduces a new, faster diffusion mechanism that a step change in grain size would occur between the doped samples and the undoped sample. This is the case, but only for the sample sintered at $1450{ }^{\circ} \mathrm{C}$, and may just be due to the grain growth effects discussed previously. Therefore, while it is possible that liquid phase sintering or viscous flow is the mechanism by which diffusion is improved, it is not possible to make a conclusion based on the present results. In order to determine the mechanism, it would probably be necessary to perform a more detailed study of grain growth variation with sintering time, which would allow the calculation of the activation energy and sintering exponent.

\subsection{Conductivity}

The samples for conductivity measurements were sintered at $1450{ }^{\circ} \mathrm{C}$ for $4 \mathrm{~h}$. This sintering regime was used as it is close to the regime found to give maximum conductivity for $\mathrm{Ce}_{0.8} \mathrm{Sm}_{0.2} \mathrm{O}_{2-\delta}$ powders synthesised by the same method [25]. Therefore, the undoped sample is treated as the standard material against which the new materials should be compared. None of the strontium doped compositions showed a significant improvement in conductivity compared to the undoped sample at any measurement temperature, though the relative differences in total conductivity did change with temperature.

Whilst the trends and relative values of the results are clear, in order to establish if the results are significant, it is necessary to look at the absolute values of conductivity and compare them to the literature. First, $\mathrm{Ce}_{0.8} \mathrm{Sm}_{0.2} \mathrm{O}_{2-\delta}$ will be considered in order to establish the validity of the reference sample. The total conductivity of the $\mathrm{Ce}_{0.8} \mathrm{Sm}_{0.2} \mathrm{O}_{2-\delta}$ sample at $600{ }^{\circ} \mathrm{C}$ was $0.020 \pm 0.001 \mathrm{~S} \mathrm{~cm}^{-1}$, whilst that of a sample synthesised by Kosinski et al. [25] using the same method, though sintered at $1450{ }^{\circ} \mathrm{C}$ for $6 \mathrm{~h}$, had a similar total conductivity of $0.018 \mathrm{~S} \mathrm{~cm}^{-1}$ at $600{ }^{\circ} \mathrm{C}$. The similarity of the values confirms that the sample is a reliable standard. For a broader comparison, the total conductivity at $600{ }^{\circ} \mathrm{C}$ of the $\mathrm{Ce}_{0.8} \mathrm{Sm}_{0.2} \mathrm{O}_{2-\delta}$ sample in other studies on strontium doping varies from $0.0031 \mathrm{~S} \mathrm{~cm}^{-1}$ (Gao et al.) [19] to $0.013 \mathrm{~S} \mathrm{~cm}^{-1}$ (Jaiswal et al.) [22], respectively, $85 \%$ and $35 \%$ less conductive than the same sample in this study. This wide range of conductivities for materials which are nominally the same is mostly due to variation in the grain boundary conductivity. While this comparison of $\mathrm{Ce}_{0.8} \mathrm{Sm}_{0.2} \mathrm{O}_{2-\delta}$ samples is useful to compare the baseline, the most useful comparison, in terms of absolute values of conductivity, is between the conductivity of the most conductive sample in this and other studies on strontium doping. For total conductivity at $600{ }^{\circ} \mathrm{C}$, the conductivity of $\mathrm{Ce}_{0.8} \mathrm{Sm}_{0.2} \mathrm{O}_{2-\delta}$ in this study $\left(0.020 \mathrm{~S} \mathrm{~cm}^{-1}\right)$ compares favourably to the highest total conductivities in other studies which include, $\left.0.008 \mathrm{~S} \mathrm{~cm}^{-1}\left(\mathrm{Ce}_{0.8}\left(\mathrm{Sm}_{0.7} \mathrm{Sr}_{0.3}\right)_{0.2}\right) \mathrm{O}_{2-\delta}\right)$, [19] $0.007 \mathrm{~S} \mathrm{~cm}^{-1}\left(\mathrm{Ce}_{0.78} \mathrm{Sm}_{0.2} \mathrm{Sr}_{0.02} \mathrm{O}_{1.88}\right)$, [11] $0.013 \mathrm{~S} \mathrm{~cm}^{-1}\left(\mathrm{Ce}_{0.79} \mathrm{Gd}_{0.2} \mathrm{Sr}_{0.01} \mathrm{O}_{1.9-\delta}\right)$, [16] and $0.027 \mathrm{~S} \mathrm{~cm}^{-1}\left(\mathrm{Ce}_{0.82} \mathrm{Sm}_{0.16} \mathrm{Sr}_{0.02} \mathrm{O}_{1.90}\right)$ [22]. The latter sample, produced by Jaiswal et al. [22] is, in fact, the only sample in any strontium doping study to show higher conductivity than the pure $\mathrm{Ce}_{0.8} \mathrm{Sm}_{0.2} \mathrm{O}_{2-\delta}$ in this study. It should be noted that the value reported by these authors is significantly higher than any published previously for any aliovalently doped ceria. Therefore, further work to confirm such a significant effect in the case of strontium-doping with constant oxygen vacancy concentration would be desirable. The implication of this comparison of conductivity values of the most conductive samples is that strontium co-doping may not be an effective strategy to increase the conductivity of aliovalently doped ceria materials past that of the best existing materials.

In order to gain an understanding of the causes of the changes in total conductivity the bulk and grain boundary conductivity components must be considered. Generally, the bulk conductivity depends mostly on the intrinsic conductivity of the material, while the grain boundary conductivity depends on the microstructure and grain boundary composition as well as the intrinsic conductivity [33]. As can be seen in Figure 11, changes in total 
conductivity are the result of corresponding changes in both the bulk and grain boundary components of conductivity. By examining each component in turn, the changes in total conductivity can be explained.

The grain boundary conductivity will be considered first to explain microstructural and processing effects, then the remaining intrinsic effects will be considered. It is generally found that the intrinsic conductivity of the grain boundary is directly linked to that of the bulk, if microstructural and impurity effects are discounted. Therefore, it is useful to consider the blocking factor, as this quantifies the magnitude of the grain boundary resistance, $\boldsymbol{R}_{\boldsymbol{g} \boldsymbol{b}}$, relative to the bulk resistance, $\boldsymbol{R}_{\boldsymbol{b}}$ (Equation (2)). Figure 12a shows that the blocking factor decreases with increasing strontium content. This means that the effects of strontium doping on impurities at the grain boundary or on the microstructure must be beneficial. Figure 12a also shows, however, that the decrease is not linear and that the trend changes with temperature. There is a step change in blocking factor between the doped and the undoped samples, the magnitude of which decreases with increasing temperature. The fact that the size of this step changes with temperature implies that it is due to at least one factor other than grain size, which is invariant with temperature, and these factors will be considered after the effect of grain size is quantified. It is clear, from the results of the grain size study, that doping with strontium does lead to increased grain size and therefore will have the effect of decreasing the blocking factor. Figure 4c shows the variation of grain size with strontium content for samples sintered under the same conditions as the impedance samples. There is a notable symmetry between the shape of this curve and that of the blocking factor in Figure 11a; a jump between Sr00 and Sr02 followed by a linear section as strontium content is increased further. This suggests that the blocking factor may be strongly determined by grain size. To examine this possibility, the normalised blocking factor, plotted in Figure 12b, takes into account the expected effect of grain size on blocking factor. It appears that the normalised blocking factor also displays a step followed by a linear region. If the changes in blocking factor were due only to the changes in grain size then one would expect the normalised blocking factor to be constant for a given temperature. From Figure 12b, it appears that this may essentially be the case from 0.20 cation\% upwards, although there is still some variation. Between 0 and 0.20 cation $\%$, however, there is still a change in normalised blocking factor. This analysis of the blocking factor and the normalised blocking factor together indicate that increased grain size is responsible for the decrease in blocking factor from 0.20 to 3 cation $\%$ strontium doping. As the decrease from 0 to $0.20 \%$ is not fully accounted for by grain size, however, it must be due to a change in the structure or local composition of the grain boundary. It is likely that this is related to silicon impurities. As discussed in the Introduction, it has been reported that only a few cation\% of strontium doping is sufficient to mitigate the effects of hundreds of ppm of silicon impurity [10,12]. XRF analysis shows the level of silicon in the samples of the current study to be less than 10ppm. It is therefore probable that 0.20 cation $\%$ addition of strontium is sufficient to fully mitigate the effects of silicon impurities in these samples and that further additions will not have any further effect in this regard. This would result in the variation of the normalised blocking factor with strontium content that we observe. In summary, there are improvements in the blocking factor with increasing strontium content due to silicon scavenging and increased grain size. Now, considering this analysis of the blocking factor the trends in grain boundary conductivity can be explained. The observed grain boundary conductivity at $300^{\circ} \mathrm{C}$, shown in Figure $11 \mathrm{c}$, shows a slight increase up to 0.5 cation $\%$ strontium followed by a decrease. This trend results from the combination of positive local effects on the grain boundary, described by the blocking factor, and the underlying decrease in intrinsic bulk conductivity, which can be seen in Figure 11b. In addition, the trend in the activation energy associated with grain boundary processes in Figure 9 shows a minimum at 0.20 cation $\%$ strontium. It is probable that this too is linked to the scavenging of silicon by strontium, so reducing the overall energy barrier to conduction of the grain boundaries. 
The bulk component of the conductivity will now be examined. As previously explained, once microstructural factors are accounted for, the intrinsic conductivity of the bulk is the main factor in determining the overall trend in total conductivity. The changes in bulk conductivity with strontium content will be discussed with reference to the oxygen vacancy concentration, average dopant ionic radius and the valency of the dopants. Oxygen vacancies play a crucial role by enabling oxygen mobility. However, if the vacancy concentration is too high the vacancies tend to cluster and become trapped leading to a decrease in ionic conductivity. As a result, in aliovalently doped ceria, a vacancy concentration of $0.05-0.1$ is found to be optimal, depending on the identity of the dopants and the measurement temperature. Dopant ionic radius is also considered to have an optimal value and this is often thought of in terms of minimisation of the elastic strain in the lattice which occurs due to the mismatch between the radius of the dopant cation and that of the host lattice. Finally, dopant valency is observed to strongly affect conductivity with trivalent dopants, resulting in consistently higher conductivities than for divalent dopants. It can be seen from Figure $8 \mathrm{a}$ that increasing strontium doping decreased the bulk conductivity at all temperatures for which the components of conductivity could be resolved. It is well established that the oxygen vacancy concentration and average dopant radius are the two main variables which must be optimised to maximise conductivity in aliovalently doped ceria [34-36]. As $\mathrm{Ce}_{0.8} \mathrm{Sm}_{0.2} \mathrm{O}_{2-\delta}$ is known to be near optimal in these respects at intermediate temperatures, changes in these two variables may have a negative impact on conductivity. Assuming ideal behaviour, as the strontium content in the samples increased up to the maximum of 3 cation \% the molar oxygen vacancy concentration would increase from 0.10 to 0.13 and the average dopant radius would increase from 1.079 to $1.100 \AA$ A Generally, variations in conductivity of doped ceria with vacancy concentration and dopant ionic radius follow distinct trends which allow a comparison to be made with the samples in this study. These trends are studied by varying the dopant concentration or dopant species, respectively. A comparison between the magnitude of the changes in conductivity in this study with selected others should reveal the likely reasons for the decrease in bulk conductivity with increasing strontium content.

Considering first the effect of vacancy concentration, a comparison can be made with purely samarium doped ceria. The effect of an increase from 20 mole $\%$ to 25 and 30 mole $\%$ samarium-i.e., a 25 or $50 \%$ increase in oxygen vacancy concentration-on total conductivity - has been reported [25,37-39]. All of these studies found a decrease in total conductivity at intermediate temperatures when molar oxygen vacancy concentration was increased beyond 0.1. Kosinski et al. [25] provide directly comparable conductivity values for the bulk component of conductivity for oxygen vacancy concentrations of $0.1\left(\mathrm{Ce}_{0.8} \mathrm{Sm}_{0.2} \mathrm{O}_{2-\delta}\right)$ and $0.15\left(\mathrm{Ce}_{0.7} \mathrm{Sm}_{0.3} \mathrm{O}_{2-\delta}\right)$ at $300{ }^{\circ} \mathrm{C}$. Interpolating linearly between the bulk conductivity of the two samples at $300{ }^{\circ} \mathrm{C}$ gives an approximate value of $50 \%$ for the expected decrease in bulk conductivity for an increase in vacancy concentration from 0.10 to 0.13 . Therefore, by comparison with the $76 \%$ decrease in bulk conductivity observed on going from Sr00 to $\mathrm{Sr} 30$ at $300{ }^{\circ} \mathrm{C}$, it seems likely that the majority of the decrease in bulk conductivity observed in the present study is a result of the increase in oxygen vacancy concentration.

Now the effect of the variation in average dopant radius will be examined. It is increasingly considered to be the case that the change in bulk conductivity with varying average dopant radius for co-doped materials follows a similar trend to singly doped materials [40-42]. The average dopant radius of $1.10 \AA$, for Sr30, is intermediate between those of Sm, $1.079 \AA$, and Nd, $1.109 \AA$. Salih et al. found the bulk conductivity of $\mathrm{Ce}_{0.8} \mathrm{Nd}_{0.2} \mathrm{O}_{2-\delta}$ at $300{ }^{\circ} \mathrm{C}$ to be $7.2 \times 10^{-5} \mathrm{~S} \mathrm{~cm}^{-1}$. Interpolating between that value and the bulk conductivity of $\mathrm{Ce}_{0.8} \mathrm{Sm}_{0.2} \mathrm{O}_{2-\delta}$ at $300{ }^{\circ} \mathrm{C}$ from the present study, $9.5 \times 10^{-5} \mathrm{~S} \mathrm{~cm}^{-1}$, implies a decrease in conductivity of $17 \%$ due to decreased average ionic radius on going from Sr00 to $\mathrm{Sr} 30$.

A final change which occurs with strontium doping, which has not yet been addressed, is the divalency of the $\mathrm{Sr}^{2+}$ cations compared to the trivalency of $\mathrm{Sm}^{3+}$. It has been noted 
that the attraction of a strontium cation, which has an effective charge of $2-$, for an oxygen ion vacancy, which has an effective charge of $2+$, is likely to be stronger than that of a samarium cation, which has an effective charge of only $-1[15,19]$. In addition to this, a computational study showed that the binding energy of divalent dopant clusters is higher than for trivalent clusters [29]. The implication of this increased attraction is that divalent doping would lead to fewer free vacancies and therefore lower ionic conductivity. It is the case that divalently doped ceria generally shows lower ionic conductivity than trivalently doped [26]. Therefore, it would be expected that this may be responsible for a small part of the decreased bulk conductivity observed in these samples.

In summary, the observed decreases in conductivity are most likely to be due to a combination of increased oxygen vacancy concentration, increased average dopant ionic radius and the presence of more strongly charged strontium cations. The oxygen vacancy concentration is responsible for the majority of the decrease, with a large minority due to the ionic radius and a minor amount due to the more strongly charged cations.

\section{Conclusions}

A low temperature chemical method was successfully employed to prepare the compositional series $\mathrm{Ce}_{0.8-\mathrm{x}} \mathrm{Sm}_{0.2} \mathrm{Sr}_{\mathrm{x}} \mathrm{O}_{2-\delta}$ with $\mathrm{x}=0$ to 0.04 . By XRD, these products were found to be phase-pure mixed oxides with the fluorite structure and to obey Vegard's law. Silicon impurity levels were found to be below $10 \mathrm{ppm}$ by XRF, and this was attributed to the synthesis method used. The materials consisted of fine powders whose crystallite sizes were between 6.5 and $11 \mathrm{~nm}$ and decreased with increasing strontium content. On pressing the pellets and firing at $1450{ }^{\circ} \mathrm{C}$ for $4 \mathrm{~h}$, increasing strontium content caused relative density to increase to a plateau above 1 cation $\%$ and gave rise to a dramatic, almost linear increase in grain size. Grain size data for each composition fitted well to log normal distributions.

In impedance measurements, the grain boundary arcs were much smaller than the bulk arcs in all impedance spectra. Bulk (or intrinsic) conductivity decreased monotonically with increasing strontium content and total conductivity followed the same trend. The grain boundary conductivity, however, passed through a maximum at low strontium content, at around 0.20 cation mole $\%$, before falling steadily as strontium content increased further. It is interesting that the activation energies for total and bulk conductivity increased roughly linearly with increasing strontium content whereas, for grain boundary conductivity, the activation energy passed through a minimum - also at around 0.20 cation mole $\%$ - before rising as strontium content increased above this value.

Total conductivity of the undoped material at realistic operating temperatures for intermediate temperature SOFCs $\left(\sim 600^{\circ} \mathrm{C}\right)$ compared very favourably with values reported in the literature for doped cerias. $\mathrm{SrO0}$ had the highest total conductivity at all measurement temperatures except at the highest, $800^{\circ} \mathrm{C}$, at which $\mathrm{Sr} 02$ had a similar value.

To consider the trends in the grain boundary and bulk in more detail, first the blocking factor, the ratio of grain boundary to bulk resistance, was plotted against strontium content. The blocking factor showed a gentle decrease with increasing strontium content from 0.50 cation $\%$ upwards, but exhibited a sharp drop on passing from the undoped sample to the 0.20 cation mole $\%$ sample. This step feature was reduced in size, but persisted, when blocking factor was normalised to remove the effect of increasing grain size with increasing strontium content. This step-which coincides with both the maximum in grain boundary conductivity and the minimum in the activation energy of grain boundary conductivity - was attributed to the improvement of grain conductivity caused by the scavenging of silicon impurities by this small addition of strontium. Since silicon levels were low in these materials, a small amount of dopant was expected to be sufficient to fully mitigate the effects of silicon impurities. It is expected, therefore, that in more heavily Si-contaminated samples, higher degrees of Sr doping would be beneficial.

By separating the contributions first of bulk and grain boundary, and then of the effect of grain size, to the ionic conductivity of these samples, it has been possible to elucidate the individual effects of strontium doping. 


\begin{abstract}
Author Contributions: Conceptualization, R.T.B. and T.S.; methodology, R.T.B. and T.S.; formal analysis, T.S. and R.T.B.; investigation, TS; resources, R.T.B.; data curation, T.S.; writing-original draft preparation, T.S.; writing-review and editing, R.T.B. and T.S.; supervision, R.T.B.; project administration, R.T.B.; funding acquisition, R.T.B. All authors have read and agreed to the published version of the manuscript.
\end{abstract}

Funding: This research received no external funding. The APC was waived by the publishers.

Data Availability Statement: The dataset supporting this research is available at: http:/ /www.standrews.ac.uk/profile/rtb5 (accessed on 9 August 2021).

Acknowledgments: We thank the School of Chemistry, University of St Andrews for a studentship for T.S. Electron microscopy was carried out at the Electron Microscopy Facility, University of St Andrews.

Conflicts of Interest: There are no conflict of interest.

\title{
References
}

1. Minh, N.M.; Takahashi, T. Science and Technology of Ceramic Fuel Cells, 1st ed.; Elsevier: New York, NY, USA, 1995; pp. 1-14.

2. Sharifzadeh, M. (Ed.) Design and Operation of Solid Oxide Fuel Cells: The Systems Engineering Vision; Elsevier: New York, NY, USA, 2019.

3. Fergus, J.W.; Hui, R.; Li, X.; Wilkinson, D.P.; Zhang, J. (Eds.) Solid Oxide Fuel Cells: Materials Properties and Performance; CRC Press: Boca Raton, FL, USA, 2019.

4. Huang, K.; Goodenough, J.B. Solid Oxide Fuel Cell Technology: Principles, Performance and Operations; Elsevier: New York, NY, USA, 2009.

5. Wachsman, E.D.; Lee, K.T. Lowering the Temperature of Solid Oxide Fuel Cells. Science 2011, 334, 935-939. [CrossRef]

6. Jacobson, A.J. Materials for Solid Oxide Fuel Cells. Chem. Mater. 2010, 22, 660-674. [CrossRef]

7. Leah, R.; Bone, A.; Lankin, M.; Selcuk, A.; Pierce, R.; Rees, L.; Corcoran, D.; Muhl, P.; Dehaney-Steven, Z.; Brackenbury, C.; et al. Low-Cost, REDOX-Stable, Low-Temperature SOFC Developed by Ceres Power for Multiple Applications: Latest Development Update. ECS Trans. 2013, 57, 461-470. [CrossRef]

8. Coles-Aldridge, A.V.; Baker, R.T. Ionic conductivity in multiply substituted ceria-based electrolytes. Solid State Ion. 2018, 316, 9-19. [CrossRef]

9. Coles-Aldridge, A.V.; Baker, R.T. Oxygen ion conductivity in ceria-based electrolytes co-doped with samarium and gadolinium. Solid State Ion. 2020, 347, 115255. [CrossRef]

10. Lane, J.; Neff, J.; Christie, G. Mitigation of the deleterious effect of silicon species on the conductivity of ceria electrolytes. Solid State Ion. 2006, 177, 1911-1915. [CrossRef]

11. Yeh, T.-H.; Chou, C.-C. Ionic conductivity investigation in samarium and strontium co-doped ceria system. Phys. Scr. 2007, T129, 303-307. [CrossRef]

12. Kim, D.K.; Cho, P.S.; Lee, J.-H.; Kim, D.-Y.; Park, H.-M.; Auchterlonie, G.; Drennan, J. Mitigation of highly resistive grain-boundary phase in gadolinia-doped ceria by the addition of SrO. Electrochem. Solid-State Lett. 2007, 10, 91-95. [CrossRef]

13. Cioateră, N.; Pârvulescu, V.; Rolle, A.; Vannier, R.N. Effect of strontium addition on europium-doped ceria properties. Solid State Ion. 2009, 180, 681-687. [CrossRef]

14. Ramesh, S.; Reddy, C.V. Properties of $\mathrm{Al}_{2} \mathrm{O}_{3}-\mathrm{Sm}_{2} \mathrm{O}_{3}-\mathrm{CeO}_{2}$ electrolyte. Acta Phys. Pol. A 2009, 115, 909-913. [CrossRef]

15. Zheng, Y.; He, S.; Ge, L.; Zhou, M.; Chen, H.; Guo, L. Effect of Sr on Sm-doped ceria electrolyte. Int. J. Hydrog. Energy 2011, 36, 5128-5135. [CrossRef]

16. Buchi Suresh, M.; Johnson, R. The effect of strontium doping on densification and electrical properties of $\mathrm{Ce}_{0.8} \mathrm{Gd}_{0.2} \mathrm{O}_{2-\delta}$ electrolyte for IT-SOFC application. Ionics 2012, 18, 291-297.

17. Ramesh, S.; Raju, K.C.J.; Reddy, C.V. Synthesis and Characterization of Co-Doped Ceria Ceramics by Sol-Gel Method. Trans. Indian Ceram. Soc. 2011, 70, 143-147. [CrossRef]

18. Júnior, J.M.S.; Malta, L.F.B.; Garrido, F.M.S.; Ogasawara, T.; Medeiros, M.E. Raman and Rietveld structural characterization of sintered alkaline earth doped ceria. Mater. Chem. Phys. 2012, 135, 957-964. [CrossRef]

19. Gao, Z.; Liu, X.; Bergman, B.; Zhao, Z. Enhanced ionic conductivity of $\mathrm{Ce}_{0.8} \mathrm{Sm}_{0.2} \mathrm{O}_{2-\delta}$ by Sr addition. J. Power Sources 2012, 208, 225-231. [CrossRef]

20. Horovistiz, A.L.; Muccillo, E.N.S. Microstructural and electrical characterizations of chemically prepared $\mathrm{Ce}_{0.8} \mathrm{Gd}_{0.2-x}\left(\mathrm{Ag}_{\mathrm{g}}\right.$ Sr) $)_{x} \mathrm{O}_{1.9}(0 \leq x \leq 0.02)$. Solid State Ion. 2012, 225, 428-431. [CrossRef]

21. Jaiswal, N.; Kumar, D.; Upadhyay, S.; Parkash, O. Effect of Mg and Sr co-doping on the electrical properties of ceria-based electrolyte materials for intermediate temperature solid oxide fuel cells. J. Alloy. Compd. 2013, 577, 456-462. [CrossRef]

22. Jaiswal, N.; Upadhyay, S.; Kumar, D.; Parkash, O. $\mathrm{Sm}^{3+}$ and $\mathrm{Sr}^{2+}$ co-doped ceria prepared by citrate-nitrate auto-combustion method. Int. J. Hydrog. Energy 2014, 39, 543-551. [CrossRef]

23. Kashyap, D.; Patro, P.K.; Lenka, R.K.; Mahata, T.; Sinha, P.K. Effects of Gd and Sr co-doping in CeO2 for electrolyte application in solid oxide fuel cell (SOFC). Ceram. Int. 2014, 40, 11869-11875. [CrossRef] 
24. Yamamura, H.; Katoh, E.; Ichikawa, M.; Kakinuma, K.; Mori, T.; Haneda, H. Multiple doping effect on the electrical conductivity in the $\left(\mathrm{Ce}_{1-x-y} \mathrm{Lax} \mathrm{M} y\right) \mathrm{O}_{2-\delta}(\mathrm{M}=\mathrm{Ca}$, Sr) system. Electrochem 2000, 68, 455-459. [CrossRef]

25. Kosinski, M.R.; Baker, R.T. Preparation and property-performance relationships in samarium-doped ceria nanopowders for solid oxide fuel cell electrolytes. J. Power Sources 2011, 196, 2498-2512. [CrossRef]

26. Inaba, H.; Tagawa, H. Ceria-based solid electrolytes. Solid State Ion. 1996, 83, 1-16. [CrossRef]

27. Kilner, J. Fast oxygen transport in acceptor doped oxides. Solid State Ion. 2000, 129, 13-23. [CrossRef]

28. Chen, P.-L.; Chen, I. Role of defect interaction in boundary mobility and cation diffusivity of CeO z. J. Am. Ceram. Soc. 1994, 77, 2289-2297. [CrossRef]

29. Li, Z.-P.; Mori, T.; Zou, J. Drennan, Defects clustering and ordering in di- and trivalently doped ceria. J. Mater. Res. Bull. 2013, 48, 807-812. [CrossRef]

30. Ye, F.; Ou, D.R.; Mori, T. Microstructural evolution in a $\mathrm{CeO}_{2}-\mathrm{Gd}_{2} \mathrm{O}_{3}$ system. Microsc. Microanal. 2012, 18, 162-170. [CrossRef] [PubMed]

31. Steele, B.C.H. Appraisal of $\mathrm{Ce}_{1-y} \mathrm{Gd}_{y} \mathrm{O}_{2-y / 2}$ electrolytes for IT-SOFC operation at $500{ }^{\circ} \mathrm{C}$. Solid State Ion. 2000, 129, 95-110. [CrossRef]

32. Rahaman, M.N. Sintering of Ceramics, 1st ed.; CRC Press: Boca Raton, FL, USA, 2008; pp. 105-172.

33. Irvine, J.T.S.; Sinclair, D.C.; West, A.R. Electroceramics: Characterization by Impedance Spectroscopy. Adv. Mater. 1990, 2, $132-138$. [CrossRef]

34. Faber, J.; Geoffroy, C.; Roux, A.; Sylvestre, A.; Abelard, P. A Systematic investigation of the dc electrical conductivity of rare-earth doped ceria. Appl. Phys. A Solids Surfaces 1989, 49, 225-232. [CrossRef]

35. Balazs, G.; Glass, R. ac impedance studies of rare earth oxide doped ceria. Solid State Ion. 1995, 76, 155-162. [CrossRef]

36. Yahiro, H.; Eguchi, K.; Arai, H. Electrical properties and reducibilities of ceria-rare earth oxide systems and their application to solid oxide fuel cell. Solid State Ion. 1989, 36, 71-75. [CrossRef]

37. Huang, W.; Shuk, P.; Greenblatt, M. Properties of sol-gel prepared $\mathrm{Ce}_{1-x} \mathrm{Sm}_{x} \mathrm{O}_{2-x 2}$ solid electrolytes. Solid State Ion. 1997, 100, 23-27. [CrossRef]

38. Fu, Y.-P.; Wen, S.-B.; Lu, C.-H. Preparation and Characterization of Samaria-Doped Ceria Electrolyte Materials for Solid Oxide Fuel Cells. J. Am. Ceram. Soc. 2008, 91, 127-131. [CrossRef]

39. Yahiro, H.; Eguchi, Y.; Eguchi, K.; Arai, H. Oxygen ion conductivity of the ceria-samarium oxide system with fluorite structure. J. Appl. Electrochem. 1988, 18, 527-531. [CrossRef]

40. Yoshida, H.; Deguchi, H.; Miura, K.; Horiuchi, M.; Inagaki, T. Investigation of the relationship between the ionic conductivity and the local structures of singly and doubly doped ceria compounds using EXAFS measurement. Solid State Ion. 2001, 140, 191-199. [CrossRef]

41. Burbano, M.; Nadin, S.; Marrocchelli, D.; Salanne, M.; Watson, G.W. Ceria co-doping: Synergistic or average effect? Phys. Chem. Chem. Phys. 2014, 16, 8320-8331. [CrossRef]

42. Omar, S.; Wachsman, E.; Nino, J. A co-doping approach towards enhanced ionic conductivity in fluorite-based electrolytes. Solid State Ion. 2006, 177, 3199-3203. [CrossRef] 